University of Nebraska - Lincoln

DigitalCommons@University of Nebraska - Lincoln

Industrial and Management Systems

Industrial and Management Systems

Engineering Faculty Publications

Engineering

Winter 2005

\title{
Effects of Aging on the Biomechanics of Slips and Falls
}

Thurmon E. Lockhart

Virginia Polytechnic Institute and State University

James L. Smith

Texas Tech University

Jeffrey C. Woldstad

University of Nebraska-Lincoln, Jeffrey.Woldstad@sdsmt.edu

Follow this and additional works at: https://digitalcommons.unl.edu/imsefacpub

Part of the Operations Research, Systems Engineering and Industrial Engineering Commons

Lockhart, Thurmon E.; Smith, James L.; and Woldstad, Jeffrey C., "Effects of Aging on the Biomechanics of Slips and Falls" (2005). Industrial and Management Systems Engineering Faculty Publications. 15. https://digitalcommons.unl.edu/imsefacpub/15

This Article is brought to you for free and open access by the Industrial and Management Systems Engineering at DigitalCommons@University of Nebraska - Lincoln. It has been accepted for inclusion in Industrial and Management Systems Engineering Faculty Publications by an authorized administrator of DigitalCommons@University of Nebraska - Lincoln. 


\title{
Effects of Aging on the Biomechanics of Slips and Falls
}

\author{
Thurmon E. Lockhart, Virginia Polytechnic Institute and State University, Blacksburg, Virginia \\ James L. Smith, Texas Tech University, Lubbock, Texas \\ Jeffrey C. Woldstad, Oregon State University, Corvallis, Oregon
}

Corresponding author - Thurmon E. Lockhart, The Grado Department of Industrial and Systems Engineering,
Virginia Polytechnic Institute and State University, Blacksburg, VA 24061; lockhart@vt.edu

\begin{abstract}
Although much has been learned in recent decades about the deterioration of muscular strength, gait adaptations, and sensory degradation among older adults, little is known about how these intrinsic changes affect biomechanical parameters associated with slip-induced fall accidents. In general, the objective of this laboratory study was to investigate the process of initiation, detection, and recovery of inadvertent slips and falls. We examined the initiation of and recovery from foot slips among three age groups utilizing biomechanical parameters, muscle strength, and sensory measurements. Forty-two young, middle-age, and older participants walked around a walking track at a comfortable pace. Slippery floor surfaces were placed on the track over force platforms at random intervals without the participants' awareness. Results indicated that younger participants slipped as often as the older participants, suggesting that the likelihood of slip initiation is similar across all age groups; however, older individuals' recovery process was much slower and less effective. The ability to successfully recover from a slip (thus preventing a fall) is believed to be affected by lower extremity muscle strength and sensory degradation among older individuals. Results from this research can help pinpoint possible intervention strategies for improving dynamic equilibrium among older adults.
\end{abstract}

\section{Introduction}

Injuries associated with slip and fall accidents continue to pose a significant problem to older adults, in terms of both human suffering and economic losses. Many studies have indicated that with advancing age there is an increasing incidence of fatal slip and fall injuries (Agnew \& Suruda, 1993; Campbell, Reinken, Allan, \& Martinez, 1981; Donald \& Bulpitt, 1999; Murphy, 2000; Rubenstein et al., 1988). Falls are the leading cause of death resulting from injury among older adults (over age 75) and the second highest cause of accidental death for 45- to 75-year-olds (National Safety Council, 2002). The National Safety Council reported that in 2001, 15,400 Americans met their death by falling, and of these deaths, the majority (over $80 \%$ were people over 65 years of age (National Safety Council, 2002). In terms of the injuries, more than $25 \%$ of fall-related injuries in older adults result from slips, and $66 \%$ of fall-related hip fractures occur on wet or slippery floor surfaces (Norton, Campbell, Lee-Joe, Robinson, \& Butler, 1997). Additionally, falls and hip fractures among older adults rank among the most serious public health problems in the United States, with costs expected to exceed $\$ 43.8$ billion by the year 2020 (Englander, Hodson, \& Terregrossa, 1996). Furthermore, fall accidents are the second leading cause of work-related fatalities, after motor vehicle accidents, and compared with victims of all disabling injuries, victims of disabling falls are more likely to be older than 55 years (Courtney, Sorock, Manning, Collins, \& Holbein-Jenny, 2001 ).

A review of literature on slip and fall accidents indicates that multiple mechanisms are involved. Numerous studies have identified agerelated risk factors for falling. Factors intrinsic and extrinsic to older adults and the hazards and demands of the environment contribute to most falls in varying degrees (for a comprehen- 
sive review, refer to American Geriatrics Society et al., 2001, and Tinetti, 2003). In general, the ability to walk safely and preserve balance (keeping the body's center of mass [COM] over its base of support) in the event of a slip and fall is dependent on intact visual, vestibular, proprioceptive, and musculoskeletal systems. However, with advancing age, a variety of physiologic changes affecting these systems may interfere with gait and balance, placing older individuals at a higher risk for slip and fall accidents.

Major physiologic changes affecting the potential for slip and fall accidents begin to appear in the mid-20s. In general, isometric muscle strength peaks in the mid-20s and then decreases slowly until after 50 years of age, when there is an accelerated decline (Astrand \& Rodahl, 1986; Larsson, 1982; Rice \& Cunningham, 2001). These declines in strength development appear to stem from changes in muscle contraction mechanisms (Thelen, Schultz, Alexander, \& Ashton-Miller, 1996), in mitochondrial enzyme activity (Houmard et al., 1998), and in the proportion of fasttwitch to slow-twitch muscle fibers (Lexell, 1995). Studies suggest that age-related changes in muscle strength have an important effect on the initiation of and recovery from slip and fall accidents (Bonder \& Wagner, 1994; Larsson, Grimby, \& Karlsson, 1979; Whipple, Wolfson, \& Amerman, 1987; Wolfson, Whipple, Amerman, Kaplan, \& Kleinberg, 1985; Woolacott, 1986).

Evidence in support of this hypothesis comes from a number of investigations indicating an age-related decline in voluntary muscle strength and increased likelihood of slips and falls. Agerelated decrease in leg strength has been associated with mobility and balance problems and considered a risk factor for falls among older adults (Judge, Lindsey, Underwood, \& Winsemius, 1993; Nevitt, Cummings, Kidd, \& Black, 1989; Stephen, John, Philippa, \& Kaarin, 1994; Tinetti, Liu, \& Claus, 1993; Tinetti, Speechley, \& Ginter, 1988). For example, Wolfson et al. (1985) and Larsson et al. (1979) reported that ankle and quadriceps muscle strength was significantly lower for those who fall as compared with nonfallers. Additionally, reduced lower extremity muscle strength has been implicated as a factor contributing to nursing home placement $(\mathrm{Hu}-$ bert, Bloch, \& Fries, 1993; Wolfson, Judge, Whip- ple, \& King, 1995) and to increased risk of falling (Whipple et al., 1987).

A number of studies have documented the decline of postural control (keeping the body's COM over its base of support during quiet stance and active movement) caused by sensory degradation among older adults (Sheldon, 1963; Woolacott, Shumway-Cook, \& Nashner, 1982). This decline of postural control is believed to be an integrative process associated with a greater risk of falling (Brocklehurst, Robertson, \& James-Groom, 1982; Isaacs, 1985; Maki, Holliday, \& Topper, 1994; Overstall, Exton-Smith, Imms, \& Johnson, 1977). Sensory inputs important for balance are vision, proprioception, and vestibular sensations (Lacour, Vidal, \& Xerri, 1983; Nashner, 1982).

Vision plays a major role in maintaining stability, both at stance and while undergoing movement such as walking (Tinetti \& Speechley, 1989). Visual acuity, adaptation to the dark, peripheral vision, contrast sensitivity, and accommodation, all of which are related to stability, may be affected by age-related changes (Cohn \& Lasley, 1985; Goldman, 1986; Kornzweig, 1977). For example, age-related decrements in peripheral vision may impair an older individual's use of visual reference information. Narrowing the visual field may deprive the older person of that part of the visual field that is most sensitive to movement (Stelmach \& Worringham, 1985), and as a result, postural control may be compromised. Furthermore, elderly individuals' diminished sensitivity to low visual spatial frequencies may also lead to decreased postural stability (Lord, Clark, \& Webster, 1991). Older adults tend to rely more heavily on visual cues (e.g., the location of stable surroundings) for the maintenance of balance, whereas younger adults rely more on proprioceptive and vestibular cues. Redfern and DiPasquale (1997) reported that the postural stability of older individuals, as compared with younger individuals, was affected more by moving visual environments. They also concluded that postural instability was most likely caused by a function of the sensitivity of older people to visual and proprioceptive inputs and of their difficulty in handling sensory conflicts to the postural control system. Visual deficits then may result in an increase in the time taken for the visual system to alert the central 
nervous system to a potential fall, thereby increasing the likelihood of fall accidents.

Studies indicate that proprioceptive deficits are also significantly higher in older individuals (Rabbitt \& Rogers, 1965; Skinner, Barrack, \& Cook, 1984; Wollacott et al., 1982). The proprioceptive system contributes to stability, particularly during changes of position. Woolacott et al. (1982) demonstrated the significance of ankle proprioception for balance retention in older adults by utilizing a moveable platform that permitted stabilization of either the visual field or the support surface. Comparing the postural sway, they found that older individuals had large increases in postural sway when ankle proprioception was eliminated (via a moveable platform). This large increase in postural sway was associated with a greater risk of falling (Isaacs, 1985). Proprioceptive information also plays a vital role in modification of internal models using feed-forward control mechanisms (Bard, Fleury, Teasdale, Paillard, \& Nougier, 1995; Sainburg, Ghilardi, Poizner, \& Ghez, 1995). During slip perturbation, motor programs have to be modified to maintain dynamic stability. Modification of the motor program is closely associated with visual input as well as proprioceptive input (plantar cutaneous receptors, muscle and joint mechanoreceptors). However, when visual cues conflict with environmental cues, proprioceptive input may be the quickest and most accurate modality associated with balance maintenance (Ghez \& Sainburg, 1995). As a result, older adults' proprioceptive deficits may hinder optimum balance recovery during slip-induced perturbations and increase the likelihood of fall accidents.

Studies on the vestibular system indicate a marked decline in the vestibular apparatus among older adults (i.e., reduction of hair cells of the cristae ampullares [semicircular canals] and of the macula of the utriculus and sacculus; Johnsson \& Hawkins, 1972; Rosenhall \& Rubin, 1975). The major contribution of the vestibular apparatus to posture is in maintaining the whole-body balance by perceiving the changes in direction as well as motion by adjusting the activity of the postural muscles (Inglis, Shupert, Hlavacka, \& Horak, 1995; Keshner, Allum, \& Pfaltz, 1987). In the normal state, vestibular receptors in each labyrinth generate resting activity; subsequent head movement produces equal and opposite alteration in the activity in each ear. This in turn leads to the appropriate compensatory eye and muscle response for maintenance of posture. As indicated, the vestibular system contributes to stabilizing the eyes and head in space but is also important during fast postural movements (Petersen, Magnusson, Fransson, \& Johansson, 1994), such as in eliciting fall responses (Melvill \& Watt, 1971a, 1971b) and in resolving conflicting visual and proprioceptive information (Nashner, 1982). As a result, older adults' degraded vestibular system may hinder the optimum balance recovery response and may increase their likelihood of slips and falls (Kristinsdottir, Jarnlo, \& Magnusson, 2000).

Increasing age can also have an effect on gait because of postural and balance changes. Older adults tend to have a shorter step length and a broader walking base, which results in an increase in stance time and double support time (Gillis, Gilroy, Lawley, Mott, \& Wall, 1986; Imms \& Edholm, 1979; Murray, Kory, \& Clarkson, 1969; Winter, Patla, Frank, \& Walt, 1990). Many researchers have observed that on slippery floor surfaces, participants tend to shorten their step length in order to reduce foot velocities, foot shear forces, and the likelihood of slipping (Cooper \& Glassow, 1963, pp. 140-175; Ekkubus \& Killey, 1973). As a result, the shorter step length and the broader walking base of older adults are thought to result in a more stable or safer gait pattern; however, these gait adaptations may have some important implications for initiation of slip-induced falls. Winter et al. (1990) and Lockhart (1997) reported that horizontal heel velocity during the heel contact phase of the gait cycle was significantly higher for older participants than for younger ones, even though the walking velocity of the older participants was slower. This increase in horizontal heel velocity during a critical time of weight transfer might increase the potential for slip-induced falls if the friction between the heel and the floor is reduced by contamination of the floor surface. Thus general gait instability among older individuals, and specifically higher horizontal heel velocity during the critical phase of the gait cycle, may increase the friction demand (i.e., required coefficient of friction, or RCOF) and thereby increase the likelihood of slip-induced fall accidents. 
Although much has been learned over the last few decades about the deterioration of muscular strength, gait adaptations, and sensory degradation among older adults, information regarding the relationships between intrinsic changes associated with aging and biomechanical responses during slip-induced falls is unclear. In general, the objective of this research was to investigate the process of initiation, detection, and recovery of inadvertent slips and falls.

A hypothetical inadvertent slip and fall situation is illustrated in Figure 1, with possible causes and effects. The process is divided into four distinct phases (environment, initiation, detection, and recovery). The environmental phase considers the effects of contamination. As noted by Chaffin, Woldstad, and Trujillo (1992), "any fluid contaminant between two sliding surfaces will provide lubrication and thereby lower the dynamic COF values" (p. 285). Therefore, presence of contamination (oil, water, etc.) will reduce the available dynamic COF (ADCOF) of the floor surfaces. Consequently, slip is initiated by the combination of low DCOF and higher RCOF. As indicated earlier, initial gait characteristics such as stride length and heel velocity may affect RCOF because of the increase in horizontal foot force. If older individuals' initial gait characteristics are altered (e.g., higher heel velocity) by intrinsic deficits associated with increased age, the potential for slip-induced falls may increase. Therefore, one objective of this study was to investigate the initiation phase of unexpected slips and falls by comparing the initial gait characteristics (e.g., step length and heel velocity) of older individuals and their younger counterparts to explore the effects of gait characteristics on severity of slip initiation (i.e., RCOF).

In terms of the detection and recovery phases of slip and fall accidents, the central nervous system must undertake certain processing stages (detection phase) if a fall is to be avoided or compensated for (recovery phase). First, during the detection phase, if a potential fall is imminent, sensory input must trigger or alert those centers responsible for response selection. This alerting process may be initiated by one or more of the following sensory inputs: proprioception, vision, and vestibular function. At the input stage, any age-related disruption in the quality of the signal from the periphery may increase the likelihood of slips and falls. In addition, diminished strength of lower extremity muscles of older individuals may make it difficult to rapidly adjust the whole-body COM to prevent falls. Thus the second objective of this study was to investigate the detection and recovery phases of unexpected slips and falls by comparing sensory organization scores, strength of lower extremity muscles, and slip performance measures (e.g., slip distances, sliding heel velocity, and sliding heel acceleration) of older individuals and their younger counterparts to further explore the effects of muscular and sensory degradation on slip performance measures.

From the work conducted thus far, it is hypothesized that gait adaptations, deterioration of muscular strength, and sensory degradation among older individuals would have a greater effect on the severity of their slips and falls as com-

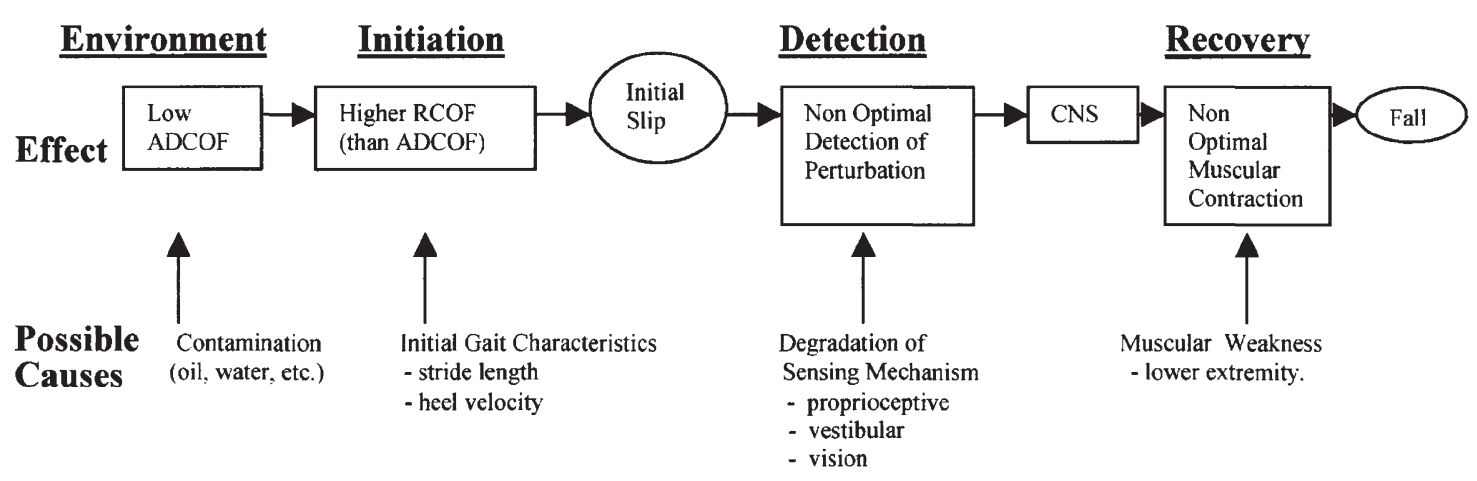

Figure 1. The process of initiation, detection, and recovery of inadvertent slips and falls with possible causes and effects. 
pared with that of their younger counterparts. In particular, it is expected that older adults' gait adaptations (e.g., shorter step length and higher heel contact velocity) would affect the friction demand characteristic at the shoe-floor interface at the time of the heel contact and increase the distance slipped initially. It is also expected that older adults' deterioration of muscular strength and sensory degradation would adversely affect the detection and recovery processes of slip and fall accidents, increasing the speed of slipping and distance slipped, ultimately leading to more falls.

\section{Relevance}

Although epidemiological studies on slip and fall accidents reveal a higher incidence of fatal injuries among older individuals, the relationship between age-related factors and slip and fall accidents is unclear. Particularly, the initiation, detection, and recovery processes associated with slipinduced falls, and age-related factors influencing these processes, are not well understood. As such the objective of this study was to investigate the process of initiation, detection, and recovery of inadvertent slips and falls. Understanding this information will help identify which of the processes associated with slip-induced falls are most critical for older adults and help pinpoint intervention strategies. Additionally, this study can provide knowledge concerning possible intervention strategies (muscle strengthening and balance exercises, etc.) for improving dynamic equilibrium.

\section{Method}

\section{Participants}

Fourteen young individuals (7 men, 7 women; age [mean, SD] $22.6 \pm 2.1$ years; height $169.7 \pm$ $6.1 \mathrm{~cm}$; weight $68.7 \pm 9.6 \mathrm{~kg}), 14$ middle-age individuals ( 7 men, 7 women, age $46.9 \pm 13.6$ years; height $173.5 \pm 6.3 \mathrm{~cm}$; weight $75.5 \pm 16.1 \mathrm{~kg})$, and 14 older individuals ( 7 men, 7 women; age $75.5 \pm$ 6.8 years; height $170.2 \pm 6.4 \mathrm{~cm}$; weight $76.8 \pm 13.3$ $\mathrm{kg}$ ) participated in this experiment. The young participants were recruited from the general student population at Texas Tech University, and the two other groups were recruited from the local community. Most of the older participants were not engaged in regular exercise program (only 2 out of 14 individuals were involved in self-regulated exercise program). Prior to participating in the experiment, older participants were examined by a physician to ensure that they were in generally good physical health. Participants also received a peripheral neuropathy examination in the Neurology Department at St. Mary's Hospital in Lubbock, Texas. Participants were excluded from the study based on these tests (below $50 \%$ of the norm) and the physician's professional judgment. All participants signed a release form approved by the Texas Tech University Institutional Review Board. All participants were compensated for their time and effort.

\section{Apparatus}

Two commonly used floor materials were used in this experiment: outdoor carpet (Beau Lieu 0.25-inch [0.63 cm] Olefin) and vinyl tile (Armstrong). The vinyl tile surface was covered with motor oil (10W40) to reduce the coefficient of friction (COF). The available dynamic COF (ADCOF) for each surface was measured using a standard 4.54-kg (10-pound) horizontal pull slip meter with a rubber sole material on the force platform and found to be 1.80 for the outdoor carpet and 0.08 for the oily vinyl tile. DCOF measurements were conducted at a constant velocity of $20 \mathrm{~cm} / \mathrm{s}$. Averages of 10 measurements on each of the two floor surfaces were used as final DCOF values. Standard shoes with rubber soles were supplied to all participants to maintain constant COF levels.

Walking trials were conducted on a rectangular track using an overhead fall-arresting rig as shown in Figure 2. The wood deck was approximately $6.7 \times 6.7 \mathrm{~m}$ and permitted a straight walking path (participants were instructed to walk straight after turning). The entire deck was covered with carpet. The test surfaces (oily vinyl floor tiles) were mounted on a platform that was connected to the force plates (black box on the track; see Figure 2). A remote-controlled floor changer (RCFC) was used to change the test floor surfaces so as to provide unexpected slippery conditions. The RCFC unit was composed of a DC motor (LEESON Electric Corp.) and a gliding shaft (ACME Thread) attached to a platform. The DC motor was controlled 


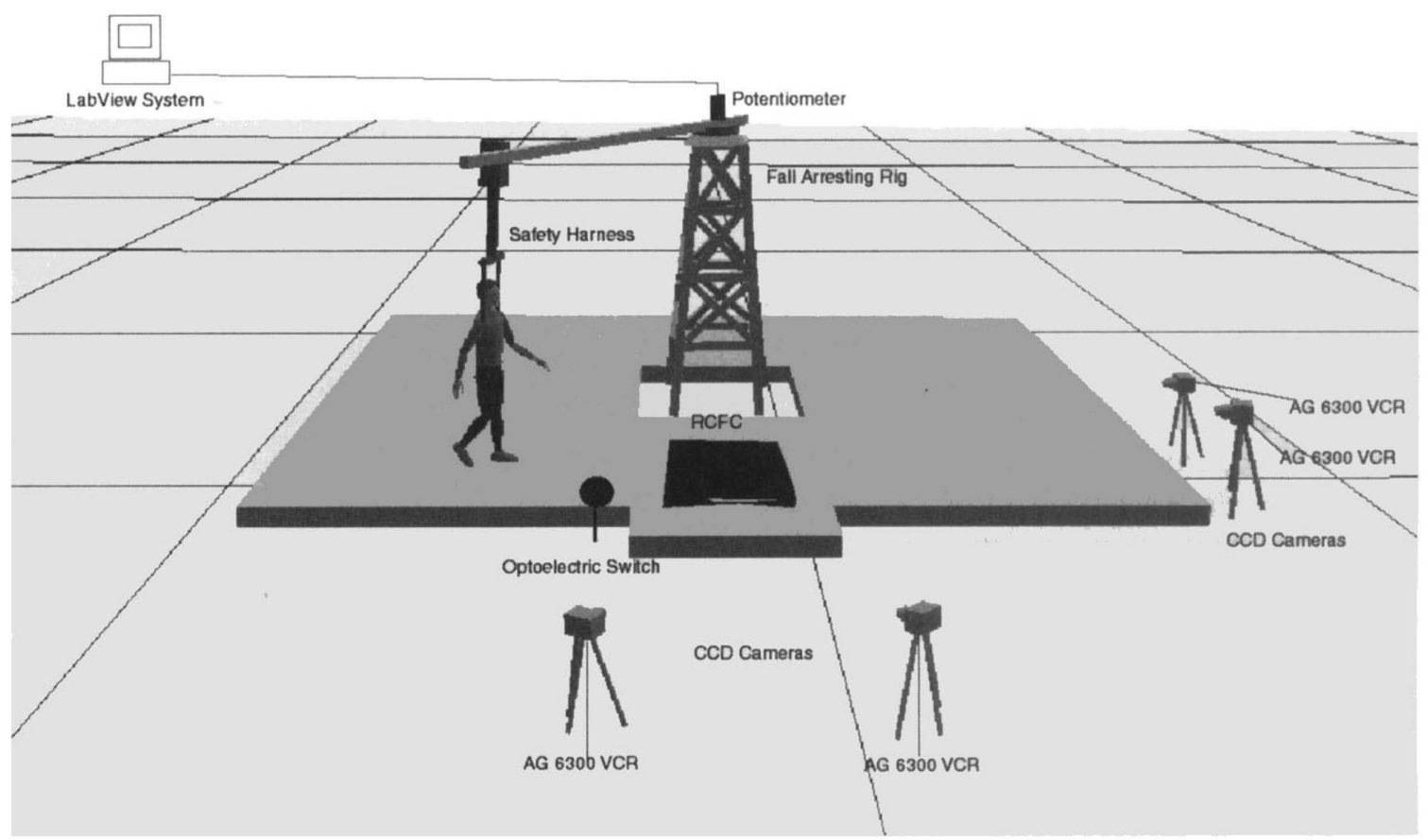

Figure 2. Field layout of the experiment, including fall-arresting rig, potentiometer interfaced with the LabView system, safety harness, force platforms, optoelectric switch, CCD cameras (4), AG 6300 VCR (4), and remote control floor changer (RCFC) units with baseline carpet floor material

by a remote control unit. Once triggered, the DC motor turned the ACME Thread (maximum 1750 revolutions/min), thereby moving the platform to a desired floor level. The test surfaces were mounted on a platform, which was connected to the force plates. The overall function of the system allowed a participant to walk under experimental conditions without being aware of the floor surface change.

A fall-arresting rig was used to protect participants from falling during the experiment. The rig consists of a full-body parachute harness attached to an automated overhead suspension arm. A feedback control system allowed the arm to sense the position of the participant and increase or reduce velocity to stay overhead. The rig was designed to permit the participant to fall approximately $15 \mathrm{~cm}$ before arresting the fall and stopping the forward motion. An Ariel Performance Analysis System (APAS) and four Panasonic video recorders (charge-coupled device [CCD]) were used to collect the 3-D posture data of the participants as they walked over the test surface. Twenty-six reflective markers were used to define a whole-body model. Posture data were sampled and recorded at a rate of $60 \mathrm{~Hz}$.

The ground reaction forces of the participants walking over the test surfaces were measured using two Bertec force plates (Bertec Corp., Columbus, OH) sampled at a rate of $600 \mathrm{~Hz}$. Participants were also supplied with a Walkman ${ }^{\circledR}$ (playing old comedy routines) during the walking experiment to conceal any sound of the floor changer's motors. A Sensory Organization Test (balance assessment) and a Motor Control Test were performed utilizing the NeuroTest system (NeuroCom Inc., EquiTest platform without the moving visual scene). Strength measurements were collected using a Chatillon force transducer (Itin Scale Co. Inc., Brooklyn, NY) for isometric strength tests and Cybex II (Computer Sports Medicine, Inc., Norwood, MA) for isokinetic strength tests.

\section{Procedures}

The participants were scheduled to take part in two testing sessions within 1 week's time. The participants attended a familiarization session be the fall-arresting system and walking conditions 
were introduced. Whole-body isometric strength measurements for the arms, legs, and torso were collected as described by Chaffin, Herrin, and Keyserling (1978) and Chaffin and Andersson (1991). Additionally, isokinetic strength (knee flexion) measurements were collected utilizing Cybex II. For the isokinetic strength test procedure, participants were seated with the right leg in $90^{\circ}$ flexion. Participants were instructed to push against the padded plate "as hard as you can" continuously for approximately $5 \mathrm{~s}$ after a spoken cue. Participants were allowed to practice at least one trial before data were collected. Participants were asked to apply two dynamic maximum exertions at each of three levels randomly $\left(30^{\circ}, 60^{\circ}\right.$, and $\left.90^{\circ} / \mathrm{s}\right)$. Rest periods were given after each exertion for $45 \mathrm{~s}$. The highest knee flexion torque was recorded as the isokinetic strength.

Afterward, the NeuroCom Sensory Organization Test (SOT) and Motor Control Test (MCT) were performed at the Neurology Department at St. Mary's Hospital in Lubbock, Texas, by the principal author to assess the balance profile and muscle latency (perturbation reaction time) of the participants (Cohen, Heaton, Congdon, \& Jenkins, 1996; Ford-Smith, Wyman, Elswick, \& Fernandez, 1995). Participants were asked to stand on the NeuroCom dual-force platforms with their feet in the required position on the platforms while wearing a safety harness. During the test, participants were instructed to close and open their eyes while the force plates moved forward and backward (translation) and also up and down (rotation). Individual measurements lasted $20 \mathrm{~s}$, and the total testing period lasted 20 min. For the Sensory Organization Test, there was a total of three trials for each of four conditions: Condition 1 = eyes open, stable platform; Condition 2 = eyes closed, stable platform; and Condition 3 = eyes open, sway-referenced platform (i.e., elimination of proprioceptive feedback via calibrated support surface movement associated with the participant's anteroposterior body sway); Condition $4=$ eyes closed, sway-referenced platform. For the Motor Control Tests, there were two trials for each of six conditions: Condition 1 = small forward translation of the force plates; Condition $2=$ medium forward translation of the force plates; Condition 3 = large forward translation of the force plates; Condition 4 = small backward translation of the force plates; Condition $5=$ medium backward translation of the force plates; Condition 6 $=$ large backward translation of the force plates. During the walking experiment, the participants walked (natural cadence) across each floor condition for $10 \mathrm{~min}$. A baseline measurement was collected on the carpeted floor surface before the slippery floor surface was introduced.

While walking, participants were instructed to focus their eyes on an LED located approximately $2 \mathrm{~m}$ above and $3 \mathrm{~m}$ away from the testing area. A secondary task, which required them to call out when the light was on and when it was off, was used to ensure that they attended to the LED and not the floor surface. During the 10-min session, two slippery conditions were randomly introduced by the system, and measurements of participant's posture and ground reaction forces were recorded. (For the data analysis, the second trial was used only if the first trial was not acceptable-e.g., if the participant stepped on the edge of the force platform.) Locations of the slippery surfaces were also randomly distributed by the two floor changers (e.g., two force plate locations) to provide a situation of inadvertency.

\section{Dependent Measures}

The converted coordinate data from the motion analysis system and ground reaction forces were observed during a typical slip behavior to provide robust definitions of the gait parameters. (For a comprehensive review of the dependent measures, refer to Gronqvist et al., 2001, and Lockhart, Woldstad, \& Smith, 2003.) The converted coordinate data for each of the 26 body markers (defining a 14-segment whole-body model; see Figure 3) and the ground reaction forces were digitally smoothed using a fourth-order, zero-lag, low-pass Butterworth filter (Winter, 1990) with a cutoff frequency of $6 \mathrm{~Hz}$.

\section{Gait Parameters}

Step length (SL). The linear distance in the direction of progression between successive points of foot-to-floor contact of the first foot $\left(X_{1}, Y_{1}\right)$ and other foot $\left(X_{2}, Y_{2}\right)$ was measured on both floor surfaces. The step length was calculated from 


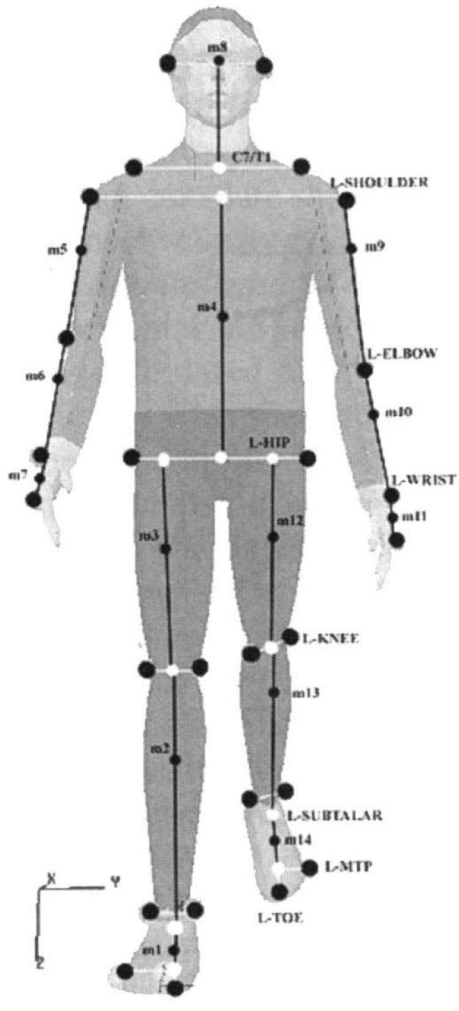

Figure 3. Locations of marker placements and internal landmarks used to generate whole-body center of mass and calculations of slip parameters.

the difference between consecutive positions of the heel contacting the floor (resultant) using the general distance formula.

Step length index (SLI). Normalized step length index was calculated by dividing the participant's step length by his or her height. Heel contact velocity $\left(V_{\mathrm{hc}}\right)$. The instantaneous horizontal (plane of progression) heel velocity $\left(V_{\mathrm{hc}}\right)$ at heel contact was calculated utilizing heel velocities in the horizontal direction at the foot displacement of $1 / 60$ $\mathrm{s}(\Delta t)$ before and after the heel contact phase of the gait cycle on both floor surfaces.

Velocity of the whole-body COM $\left(V_{\mathrm{COM}}\right)$. Sagittal and frontal link (14) segment models (Lockhart et al., 2003) were used to calculate position and velocities of the whole-body COM. The sagittal and frontal models utilized the 14-component linksegment system defined by Mackinnon and Winter (1993) and the anthropometric model (Winter, 1990). The relative horizontal COM velocity of the whole body was calculated by averaging displacement over three time intervals $(50 \mathrm{~ms})$ of the instantaneous COM velocity before the heel contact phase of the gait cycle on both floor surfaces.

Friction demand (RCOF). The required coefficient of friction (RCOF) was obtained by dividing the horizontal ground reaction force by the vertical ground reaction force $\left(F_{\mathrm{h}} / P_{\mathrm{v}}\right)$ after heel contact (Peak 3 as defined by Perkins, 1978) on the carpeted floor surface to obtain the initial friction demand.

\section{Slip Parameters}

Definitions of the slip parameters were based on the observed typical slip behavior as illustrated by Figure 4 (adapted from Lockhart, Woldstad, \& Smith, 2002). Heel contact was defined as the time when the vertical ground reaction force exceeded $10 \mathrm{~N}$.

Initially, as indicated by the horizontal heel position (Figure 4c), the heel does not slip forward. Horizontal heel velocity decreases (Figure $4 b$ ) as the heel quickly decelerates (Figure 4a) during this time period. This (no slip) is believed to be the result of the position of the whole-body COM (closer to the other stance foot; Mackinnon \& Winter, 1993) during the heel contact phase of the gait cycle. Shortly after heel contact (approximately $60 \mathrm{~ms}$, as the forefoot comes down and the COM shifts toward the sliding heel), the heel begins to slip forward (Figure 4c). Afterward, the sliding heel reaches peak sliding heel velocity (Figure $4 b$ ). During this slipping period the heel accelerates, reaching the maximum (Figure $4 \mathrm{a}$ ) near the midpoint of the sliding heel velocity profile (Figure $4 b)$. After reaching maximum heel velocity, the sliding heel velocity decreases to minimum, halting further slipping (not complete on Figure 4). Lockhart et al. (2003) indicated that the fall-arresting harness may influence slip parameters beyond certain point of slipping time. For example, Point 1 (PI) of the vertical force profile illustrates that there is a big decrease in vertical force (Figure $4 \mathrm{~d}$ ) as the participant slips (after reaching peak sliding heel velocity). This decrease in vertical force may have resulted when the participant tried to compensate for a slip by utilizing the fall-arresting harness and, in the process, may also may have affected the horizontal force profile (P2 in Figure 
a)

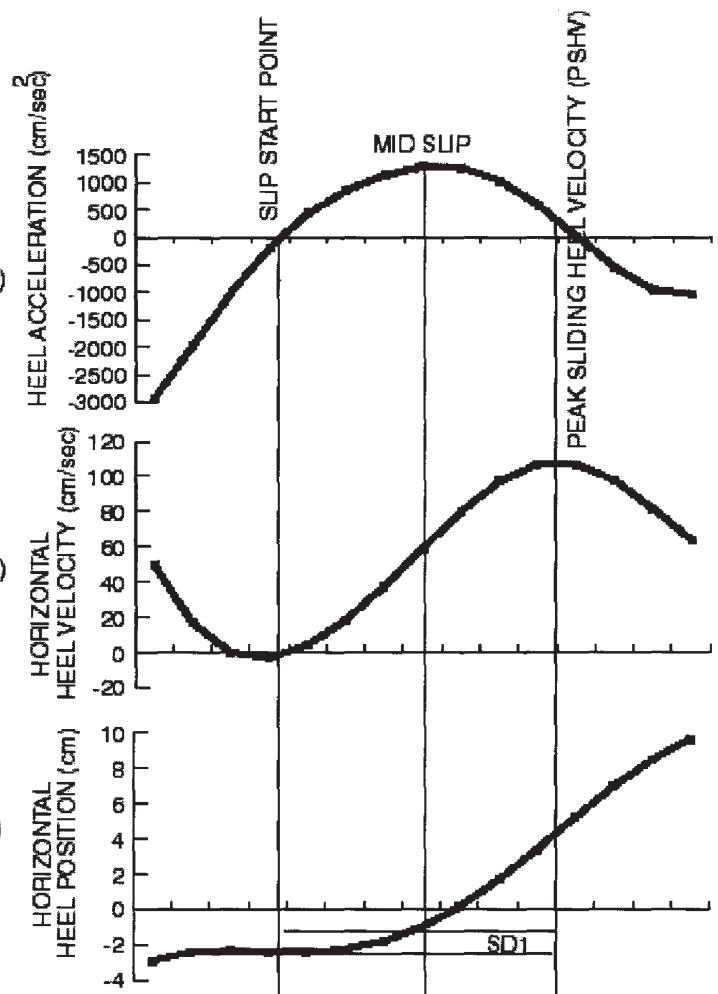

d)

e)
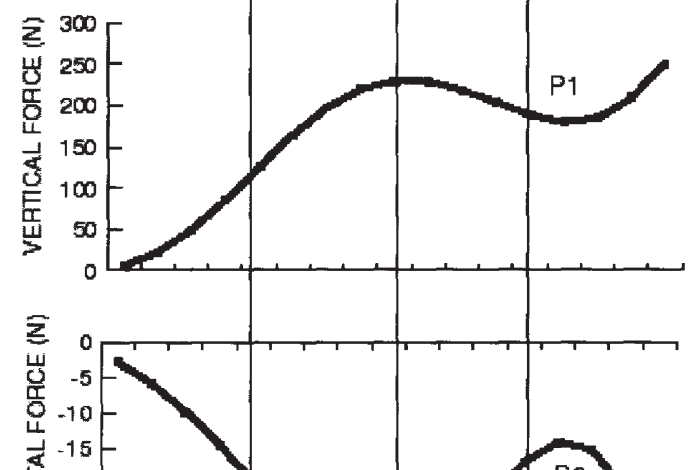

$$
\begin{aligned}
& \text { 产 }-20 \\
& \text { 섬 }-25
\end{aligned}
$$

$$
{ }_{-35}^{-30}[
$$

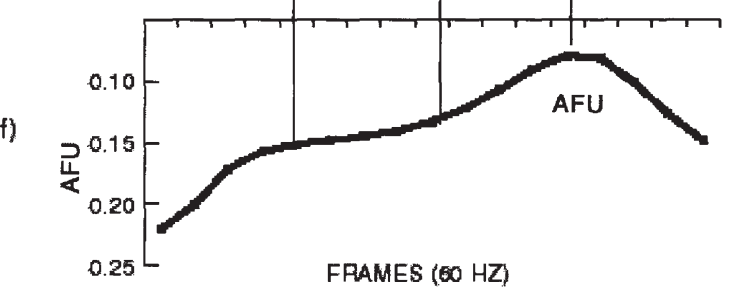

Figure 4. Composite view of the slip parameters. Adapted with permission from STP 1424 Metrology of Pedestrian Locomotion and Slip Resistance, copyright ASTM International, 100 Barr Harbor Dr., West Conshohocken, PA 19428 (Lockhart et al., 2002). 
4e). Thus, beyond the peak heel velocity point, the fall-arresting harness may affect the biomechanical parameters of slip severity (slip distance, slipping velocity, etc). Utilizing this concept, in order to represent all slip-recovery and slip-fall trials uniformly, we did not calculate slip parameters beyond the peak heel velocity point.

Adjusted friction utilization (AFU). The ratio between the horizontal and vertical ground reaction force was calculated during slip-grip responses on the oily vinyl tile floors (Figure 4f). AFU represents the ability to adjust dynamic frictional requirements during slipping (Gronqvist et al., 2001). The significance of this ratio is that it indicates when the gait compensation for a slip is most likely to occur.

Initial slip distance (SDI). The initial distance traveled by the foot after the heel contact phase of the gait cycle was measured to provide information concerning the severity of slip initiation. The slip start point was defined as the point where nonrearward positive acceleration of the foot after heel contact occurred (where the first minimum of the vertical heel velocity after the heel contact occurred), and the slip stop point for SDI was defined as the point at which peak heel acceleration occurred after the slip start point (Lockhart et al., 2003; Gronqvist et al., 2001). SDI was calculated utilizing a general distance formula.

Slip Distance II (SDII). Slip Distance II (SDII) was developed to provide information concerning the slip behavior after the initiation of slips. The start point for the SD II was defined as an SDI slip stop point and the end of slip (for the purpose of calculation) as the time when the first maximum of horizontal heel velocity occurred after the slip start point occurred (Lockhart et al., 2003; Gronqvist et al., 2001). SD II was also calculated utilizing a general distance formula.

Sliding heel velocity $\left(V_{s}\right)$. The relative sliding heel velocity $\left(V_{\mathrm{s}}\right)$ of the heel after heel contact was calculated (to assess severity of slips and falls) by averaging the instantaneous sliding heel velocity during the slip start and peak sliding heel velocity points on the oily vinyl floor surface.

Sliding heel acceleration $\left(H_{a c c}\right)$. The relative heel acceleration of the heel after heel contact was calculated by averaging the acceleration of the heel during the slip start and slip stop points on the oily vinyl floor surface.

\section{Postural Control}

Sensory Organization Test (SOT) scores. SOT scores were based on the assumption that a normal individual can exhibit anterior to posterior sway over a total range of $12.5^{\circ}\left(6.25^{\circ}\right.$ anterior, $6.25^{\circ}$ posterior) without losing balance. An overall equilibrium score was calculated by comparing the angular difference between the participant's calculated maximum anterior to posterior COM displacements to this theoretical maximum displacement (i.e., SOT scores). The result was expressed as a percentage between $0 \%$ and $100 \%$, with $0 \%$ indicating sway exceeding the limits of stability and $100 \%$ indicating perfect stability. Subcomponent scores of vision, vestibular, and proprioceptive systems were calculated via the NeuroCom system utilizing SOT conditions (see the Procedures section). Conditions 1 and 2 were used to test a participant's ability to use input from the proprioceptive system to maintain balance. Conditions 1 and 3 were used to test a participant's ability to use input from visual system to maintain balance. Conditions 2 and 4 were used to test a participant's ability to use input from the vestibular system to maintain balance (El-Kashlan et al., 1998; Ruckenstein \& Shepard, 2000).

Motor Control Test (MCT) time. The MCT time was defined as the delay (in milliseconds) between the onset of a translation and the onset of the participant's active response to the support surface movement. The muscle latency time was based on the MCT protocols utilizing the six conditions described in the Procedures section. The composite muscle latency time was determined as the average of the latency scores following medium and large translations (Black, 2001; Nashner, Black, \& Wall, 1982).

\section{Strength}

Isometric muscle strength. Whole-body isometric strength measurements were collected for the arms, legs, and torso (Chaffin \& Andersson, 1991; Chaffin et al., 1978).

Isokinetic knee flexion strength. Three isokinetic knee flexion strength measurements were collected, and the highest knee flexion torque was recorded as the isokinetic strength. 


\section{Treatment of Data}

The dependent measures - step length (SL), step length index (SLI), horizontal heel contact velocity $\left(V_{\mathrm{hc}}\right)$, and velocity of the whole-body $\mathrm{COM}\left(V_{\mathrm{COM}}\right)$-were analyzed using $3 \times 2$ (Age $\times$ Floor) two-way repeated measures analyses of variance (ANOVAs). RCOF was analyzed using a one-way ANOVA on the carpeted floor surface. Slip distances (SDI and SDII), sliding heel velocity $\left(V_{\mathrm{s}}\right)$, sliding heel acceleration $\left(H_{\text {acc }}\right)$, and adjusted friction utilization (AFU) were analyzed using one-way ANOVAS on the oily vinyl tile floor surface. Additionally, SOT scores, MCT time, and isometric/isokinetic muscle strengths were analyzed using one-way ANOVAs. Results were considered significant at $\alpha \leq .05$. For these analyses, floor (where applicable) was treated as a within-subjects effect, whereas age was a between-subjects effect.

Bivariate correlation analyses were also performed between the slip parameter (SDII) and physical parameters (SOT, MCT, and maximal isometric leg strength) in order to elaborate on the effects of sensory and musculoskeletal changes associated with aging and outcome of slips.

\section{Results}

\section{Strength}

Isometric muscle strength (arms, legs, and torso). The results of a one-way ANOVA indicated no statistically significant $(p>.05)$ arm, $F(2,39)=0.987, p$ $\approx .38$, or torso, $F(2,39)=2.25, p \approx .12$, strength differences among the age groups. However, older participants' leg strength was significantly ( $p \leq$ .05) lower than that of their younger counterparts, $F(2,39)=4.224, p \approx .02$. Post hoc comparison of means (Tukey-Kramer honestly significant difference [HSD]) indicated that the older age group's leg strength was significantly less than that of both the young and middle age groups, and the middle age group's leg strength was significantly less than that of the younger age group.

Table 1 summarizes the mean values and standard deviations for each of the dependent measures as a function of age group.

Isokinetic knee flexion strength. The results of a one-way ANOVA indicated that older participants' knee flexion strengths at each level $\left(30^{\circ} / \mathrm{s}, 60^{\circ} \%\right.$ $\mathrm{s}$, and $\left.90^{\circ} / \mathrm{s}\right)$ were all significantly $(p \leq .05)$ lower than those of their younger counterparts: $30^{\circ} / \mathrm{s}$, $F(2,39)=3.87, p \approx .03 ; 60^{\circ} / \mathrm{s}, F(2,39)=5.63, p \approx .007$; and $90^{\circ} / \mathrm{s}, F(2,39)=8.85, p \approx .0007$. Post hoc comparison of means (Tukey-Kramer HSD) indicated that the older age group's knee flexion strengths at all levels were significantly less than those of both the young and middle age groups, and the middle age group's knee flexion strength was significantly less than that of the younger group.

\section{Postural Control}

Motor Control Test (MCT) time. The results of a one-way ANOVA indicated that older participants' muscle latency times were significantly $(p \leq .05)$ longer than the those of the middle-age and younger participants, $F(2,39)=13.77, p<$ .0001. Post hoc comparison of means indicated that the older age group's MCT time was significantly longer than that of both the young and middle age groups, and the middle age group's MCT time was significantly longer than that of the younger age group.

Sensory Organization Test (SOT) scores. Older participants' SOT scores were significantly $(p \leq$ .05) lower than those of their younger counterparts, $F(2,39)=33.27, p<.0001$. Post hoc comparison of means indicated that the older age group's SOT score was significantly less than that of both the young and middle age groups, and the middle age group's SOT score was significantly less than that of the younger age group. Older adults' itemized SOT scores (somatosensory, vision, vestibular) were also significantly ( $p$ $\leq .05)$ lower than those of their younger counterparts-somatosensory, Conditions 1 and 2, $F(2$, $39)=4.61, p<.01$; vision, Conditions 1 and $3, F(2$, $39)=15.41, p<.001$; vestibular, Conditions 2 and $4, F(2,39)=27.55, p<.001-$ with post hoc comparisons similar to those discussed previously.

\section{Gait Parameters}

Step length (SL) and step length index (SLl). The result of a two-way ANOVA indicated that older participants' SL was significantly $(p \leq .05)$ shorter than that of their younger counterparts, $F(2,39)=$ $4.735, p \approx 0.01$. Similarly, older participants' SLI was significantly $(p \leq .05)$ lower than that of their younger counterparts, $F(2,39)=6.676, p \approx .003$. 
Table 1: Summary of the Dependent Variables

\begin{tabular}{|c|c|c|c|}
\hline Variables & $\begin{array}{c}\text { Young } \\
\text { (18-29 years) } \\
\text { Mean (SD) }\end{array}$ & $\begin{array}{c}\text { Middle } \\
\text { (35-59 years) } \\
\text { Mean (SD) }\end{array}$ & $\begin{array}{c}\text { Old } \\
\text { (>65 years) } \\
\text { Mean }(S D)\end{array}$ \\
\hline \multicolumn{4}{|c|}{ Maximal Isometric Strength } \\
\hline $\operatorname{Arms}(\mathrm{N})$ & $327.93(116)$ & 324.85 (114) & $278.28(85)$ \\
\hline Torso (N) & $730.46(294)$ & $699.71(287)$ & $530.35(139)$ \\
\hline $\operatorname{Leg}(\mathrm{N})^{*}$ & $923.00(333)$ & $800.78(321)$ & $577.92(164)$ \\
\hline \multicolumn{4}{|c|}{ Maximal Isokinetic Knee Flexion Strength } \\
\hline $\begin{array}{l}30^{\circ} / \mathrm{s}(\mathrm{Nm})^{*} \\
60^{\circ} / \mathrm{s}(\mathrm{Nm})^{*} \\
90^{\circ} / \mathrm{s}(\mathrm{Nm})^{*}\end{array}$ & $\begin{array}{l}58.14(17.5) \\
52.85(16.3) \\
45.71(15.0)\end{array}$ & $\begin{array}{l}55.28(18.7) \\
48.64(16.8) \\
40.21(14.5)\end{array}$ & $\begin{array}{l}41.92(12.5) \\
34.64(11.3) \\
25.57(8.94)\end{array}$ \\
\hline \multicolumn{4}{|c|}{ Sensory Organization } \\
\hline $\begin{array}{l}\text { MCT }(\mathrm{ms})^{*} \\
\text { SOT }(\%)^{*} \\
\text { Somatosensory* } \\
\text { Vision* } \\
\text { Vestibular* }\end{array}$ & $\begin{array}{r}123.78(10.8) \\
83.85(3.75) \\
94.50(1.95) \\
91.92(3.17) \\
73.07(5.37)\end{array}$ & $\begin{array}{r}131.40(7.50) \\
77.60(3.65) \\
92.64(1.96) \\
87.92(3.75) \\
64.71(7.47)\end{array}$ & $\begin{array}{r}139.70(5.20) \\
67.13(7.20) \\
90.35(5.65) \\
82.21(6.38) \\
50.00(11.1)\end{array}$ \\
\hline \multicolumn{4}{|c|}{ Gait Parameters } \\
\hline Step length $(\mathrm{cm})^{*}$ & $65.35(7.34)$ & $67.63(9.05)$ & $59.12(7.67)$ \\
\hline SL index (SLI)* & $0.38(0.04)$ & $0.39(0.04)$ & $0.34(0.03)$ \\
\hline Heel contact velocity $(\mathrm{cm} / \mathrm{s})$ & $31.03(14.5)$ & $32.11(13.5)$ & $42.31(17.9)$ \\
\hline COM velocity $(\mathrm{cm} / \mathrm{s})^{*}$ & $109.99(14.4)$ & $115.53(18.2)$ & $99.87(16.5)$ \\
\hline $\mathrm{RCOF}^{\mathrm{a}}$ & $0.176(0.01)$ & $0.188(0.02)$ & $0.192(0.02)$ \\
\hline $\mathrm{AFU}^{\mathrm{b}} *$ & $0.074(0.01)$ & $0.010(0.01)$ & $0.120(0.01)$ \\
\hline Sliding heel velocity $(\mathrm{cm} / \mathrm{s})^{\mathrm{b} *}$ & $44.05(35.1)$ & $63.95(31.7)$ & $75.84(39.7)$ \\
\hline Sliding heel acceleration $\left(\mathrm{cm} / \mathrm{s}^{2}\right)^{\mathrm{b}}$ * & $609.50(79.2)$ & $907.86(73.5)$ & $912.11(66.5)$ \\
\hline Initial slip distance (SDI; cm) ${ }^{\mathrm{b}}$ & $1.09(0.39)$ & $2.30(0.39)$ & $2.17(0.36)$ \\
\hline Total slip distance (SDII; $\mathrm{cm}$ ) $\mathrm{b}$ * & $4.98(4.81)$ & $7.65(4.92)$ & $11.80(9.43)$ \\
\hline
\end{tabular}

${ }^{a}$ Measured on carpeted floor surface only.

${ }^{\mathrm{b}}$ Measured on oily vinyl floor surface only.

* Significant $(p>.05)$ across age groups.

Additionally, there were no statistically significant $(p>.05)$ floor effects on SL, $F(2,39)=3.166$, $p \approx .05$, or SLI, $F(2,39)=3.975, p \approx .06$. Post hoc comparison of means indicated that the middle age group's SL and SLI were significantly longer and higher than those of the younger and older participants, and the older age group's SL and SLI were significantly shorter and lower than those of their younger counterparts.

Heel contact velocity $\left(V_{h c}\right)$. The result of a twoway ANOVA indicated no statistically significant $(p>.05)$ horizontal heel contact velocity $\left(V_{\mathrm{hc}}\right)$ differences among the age groups, $F(2,39)=2.0889$, $p \approx .06$. Additionally, there were no statistically significant $(p>.05)$ floor effects on $V_{\mathrm{hc}}, F(2,39)=$ $0.846, p \approx .43$.
Velocity of the whole-body COM $\left(V_{\mathrm{COM}}\right)$. The result of a two-way ANOVA indicated that older participants' VCOM was significantly $(p \leq .05)$ slower than that of their younger counterparts, $F(2,39)=4.404, p \approx .04$. Additionally, there were no statistically significant $(p>.05)$ floor effects on $V_{\mathrm{COM}^{\prime}} F(2,39)=0.846, p \approx .43$. Post hoc comparison of means indicated that the middle age group's $V_{\mathrm{COM}}$ was significantly faster than that of their younger and older counterparts, and the older age group's $V_{\mathrm{COM}}$ was significantly slower than that of the younger age group.

Friction demand (RCOF). The one-way ANOVA of RCOF indicated no statistically significant $(p>$ $.05)$ differences among the age groups, $F(2,39)=$ $2.392, p<.10$. 


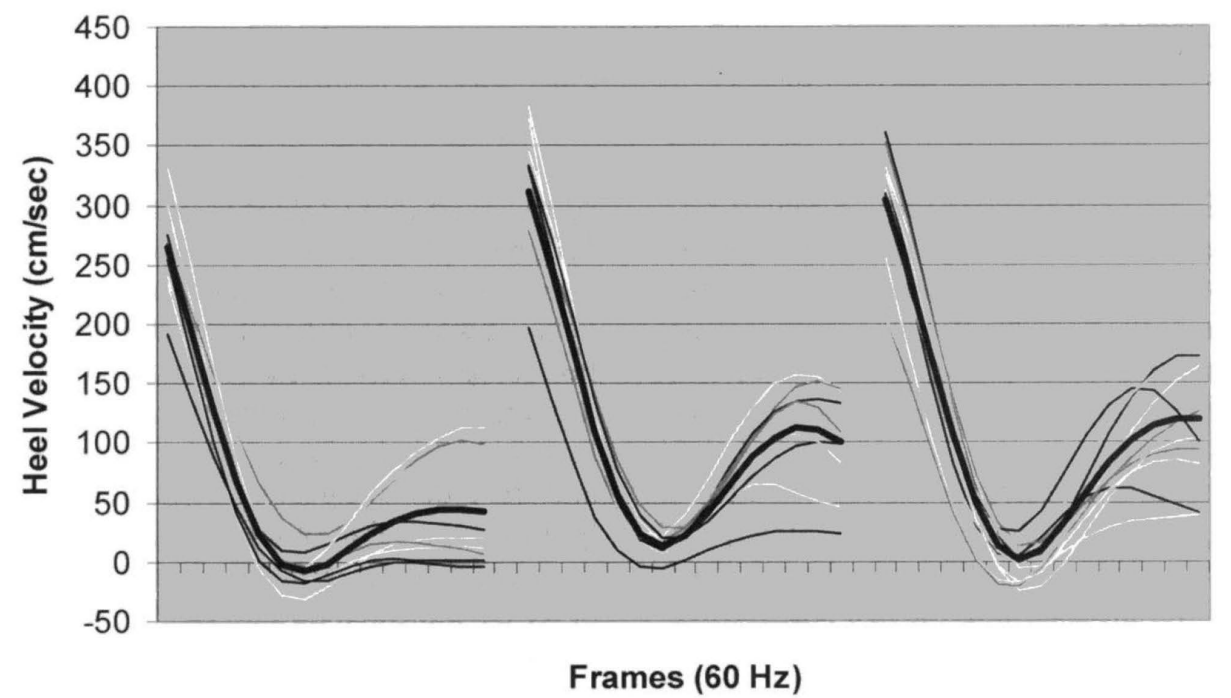

Figure 5. Heel velocity profiles of young (left panel), middle (middle panel), and older (right panel) age groups (116 ms before and $116 \mathrm{~ms}$ after heel contact). Each tick marker (frame) represents 1/60 s. Heel contact was defined as the time when the vertical ground reaction force exceeded $10 \mathrm{~N}$. The darker lines represent averages of heel contact velocities in each of the age groups.

\section{Slip Parameters}

Adjusted friction utilization (AFU). The result of the one-way ANOVA indicated that the older participants' AFU was significantly $(\mathrm{p} \leq .05)$ higher than that of their younger counterparts, $F(2,39)=$ $13.197, p<.0001$. Post hoc comparison of means indicated that the younger group's AFU was significantly lower than that of the middle and older age groups and that there were no significant differences between the middle and older age groups.

Sliding heel velocity $\left(V_{s}\right)$. The result of the oneway ANOVA indicated that older participants' $V_{\mathrm{s}}$ was significantly $(p \leq .05)$ faster than that of their younger counterparts, $F(2,39)=5.536, p<.007$. Post hoc comparison of means indicated that the older age group's $V$, was significantly faster than that of the younger participants and that there were no significant differences between the middle and older age groups. Figure 5 illustrates the results of individual trials and means (darker line) of heel velocity before heel contact $\left(V_{\mathrm{hc}}\right)$ and after heel contact $\left(V_{\mathrm{s}}\right)$ on the oily vinyl floor surface among the three age groups.

Sliding heel acceleration $\left(H_{a c c}\right)$. The result of the one-way ANOVA indicated that older participants' $H_{\text {acc }}$ was significantly $(p \leq .05)$ faster than that of their younger counterparts, $F(2,39)=$
$5.448, p<.008$. Post hoc comparison of means indicated that the older age group's $H_{\text {acc }}$ was significantly faster than that of the younger age group and that there were no significant differences between the middle and older age groups. Figure 6 illustrates the results of individual trials and means (darker line) of heel acceleration before heel contact $\left(V_{\mathrm{hc}}\right)$ and after heel contact $\left(V_{\mathrm{s}}\right)$ on the oily vinyl floor surface among young and older individuals.

Slip distances (SDI and SDII). The results of a one-way ANOVA on SDI indicated no statistically significant differences among the age groups, $F(2,39)=2.989, p \approx .06$. The results of a one-way ANOVA on SDII indicated significant differences with respect to age group, $F(2,39)=3.69, p$ $\approx .03$. Post hoc comparison of means indicated that the older age group's SDII was significantly longer than that of both the young and middle age groups and that there were significant differences between the middle and older age groups.

\section{Fall Characteristics}

Frequency of slips and falls. Slip and fall classification was obtained by comparing horizontal velocity of the whole-body COM ( $\left.V_{\mathrm{COM}}\right)$ with sliding heel velocity $\left(V_{\mathrm{s}}\right)$ of the individuals on the 


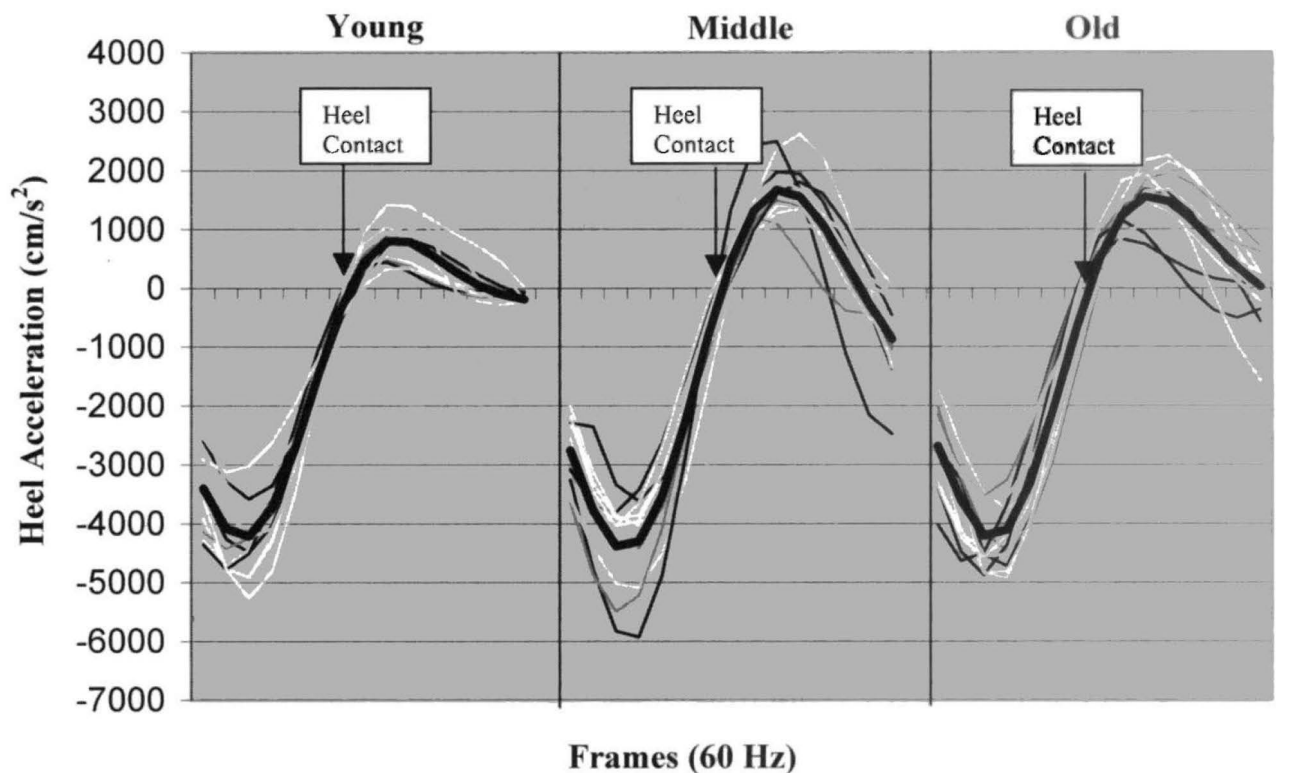

Figure 6. Sliding heel velocity profiles of three age groups (116 ms before and $116 \mathrm{~ms}$ after heel contact). Each tick marker (frame) represents $1 / 60 \mathrm{~s}$. Heel contact was defined as the time when the vertical ground reaction force exceeded $10 \mathrm{~N}$. The darker lines represent averages of sliding heel velocities in each of the age groups.

oily vinyl floor surface (during the period of slipping). In order to objectively assess an actual fall, we identified a fall as whenever two conditions were met simultaneously: (a) when the $V_{\mathrm{s}}$ was greater than the $V_{\mathrm{COM}}$ during the slipping period and (b) when the participant's body dropped toward the floor after slipping and was arrested by the harness before impact (assessed by visual inspections of video recordings of the actual fall trials). The results indicated that younger individuals experienced 4 falls, middle-age individuals experienced 8 falls, and older individuals experienced 12 falls.

Fall recovery threshold (FRT). FRT analysis was performed utilizing fallers' slip parameters (Table 2) to provide information regarding the relationship among slip parameters (initial slip distance, sliding heel velocity, and sliding heel acceleration) and fall accidents in each age groups. In other words, we investigated whether or not different age groups exhibited different threshold values (i.e., slip parameters) during a fall event. In general, when the participants in each age group exceeded the FRT limits, a fall resulted. The results of FRT analysis indicated that the younger individuals' recovery threshold was higher on the average and suggests that the recovery threshold is not all the same for the entire population. Thus, in a given situation, older individuals are at a higher risk for fall accidents (i.e., younger individuals can slip longer and faster and not fall).

Bivariate correlation analyses. Bivariate correlation analyses were performed between the slip parameter (SDII) and physical parameters (SOT, $\mathrm{MCT}$, and maximal isometric leg strength) in order to elaborate on the effects of sensory and musculoskeletal changes associated with aging and outcome of slips. In general, individuals with lower SOT scores slipped longer (Figure 7, $r=$ $.49, p \approx .005)$. The relationship between MCT and SDII indicated that individuals with higher MCT slipped longer (Figure 8, $r=.20, p \approx .03$ ).

Table 2. Slip Recovery Index Across Three Age Groups

\begin{tabular}{lccr}
\hline $\begin{array}{l}\text { Age } \\
\text { Group }\end{array}$ & $\begin{array}{c}\text { Sliding Heel } \\
\text { Velocity }(\mathrm{cm} / \mathrm{s})\end{array}$ & SDI $(\mathrm{cm})$ & $H_{\text {acc }}\left(\mathrm{cm} / \mathrm{s}^{2}\right)$ \\
\hline Young & 144.45 & 3.91 & 1580 \\
Middle & 145.26 & 3.80 & 1310 \\
Old & 107.63 & 3.12 & 1220 \\
\hline
\end{tabular}




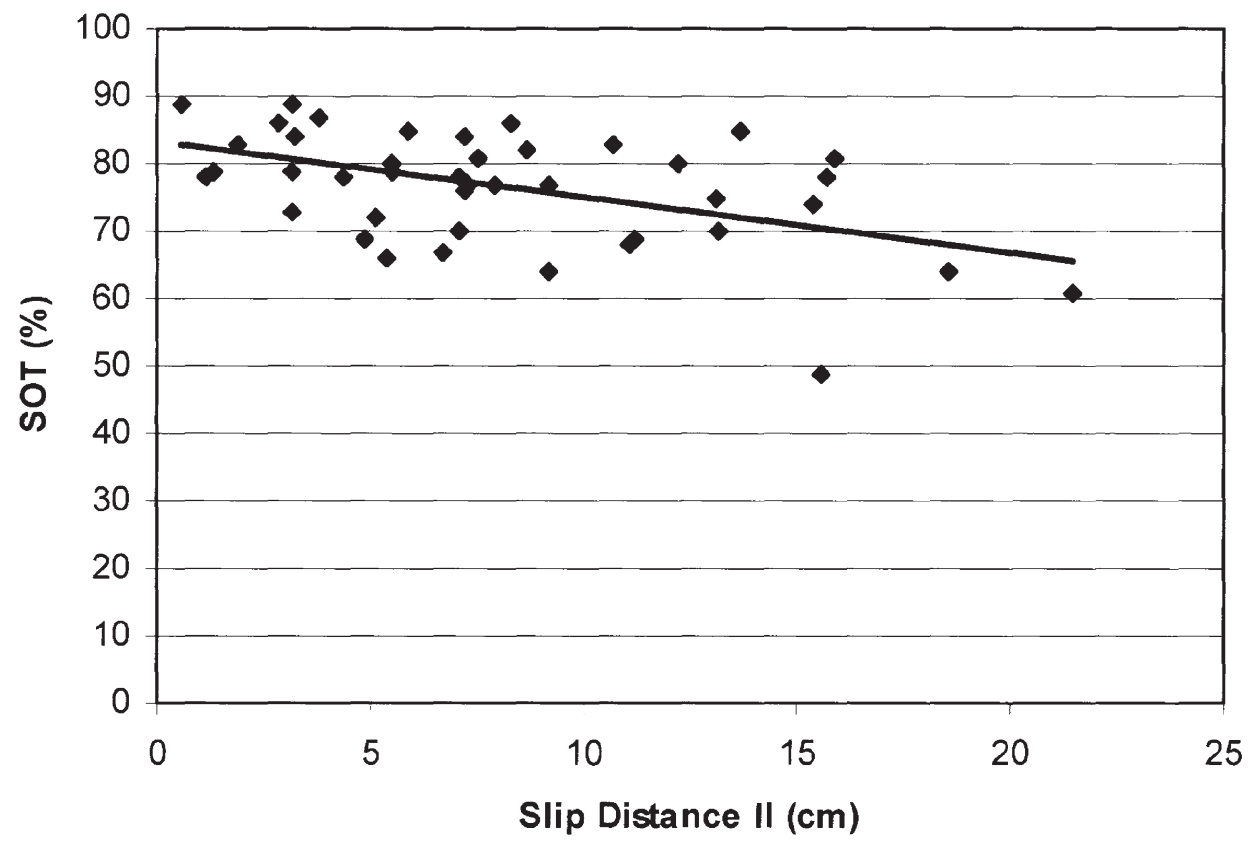

Figure 7. Relationship between distance slipped and sensory organization scores of each participants $(r=-.49)$. In general, individuals with lower SOT scores slipped farther.

Figure 8 to come.

Figure 8. The relationship between muscle latency times and distances slipped $(r=.2)$. In general, individuals with longer muscle latency times slipped farther. 
Furthermore, a relationship between SOT and MCT suggests that individuals with higher SOT scores took less time to actively respond to the support surface movements (Figure 9, $r=-0.51$, $p \approx .0002$ ). The relationship between maximal isometric leg strength and SDII indicated that individuals with stronger lower extremities slipped less (Figure 10, $r=-0.57, p \approx .002$ ). Additionally, older adults' lower extremity strength was lower than that of their younger counterparts, and they slipped longer than their younger counterparts did.

Multiple regression analysis. Multiple regression analysis was performed to describe and predict the relationship between the independent variables-age, height, weight, vision, proprioception, vestibular responses, MCT, and strength variables (strength variables were divided by the weight of the each participant) - and the dependent variables (SD: total slip distances [SDI + SDII]). The data were analyzed by utilizing techniques available for evaluating probabilistic process, functional specification of mean response, constant variance, and normality assumptions. The best subset regression method was applied to selecting the predictor variables utilizing cp (un- derspecified) and backward elimination procedure for dependent variable SD. The final model of SD is

$$
\begin{aligned}
S D= & -15.785-.037(\text { vision }) \\
& +.204(M C T-.308(L L I) \\
R^{2}= & .413, \quad F(3,38)=8.19, \quad p<.0003
\end{aligned}
$$

in which vision $=$ scores collected from Conditions 1 and 3 of computerized dynamic posturography, $M C T=$ muscle latency response times associated with medium and large support surface movements, and LLI (lower leg index) = lower leg strength/body weight. The prediction model further suggests that vision, reaction time, and muscle strength (lower extremity) were important for determining slip and fall severity (Figure 11).

\section{Discussion}

Our purpose in this study was to investigate the process of initiation, detection, and recovery of inadvertent slips and falls-more specifically, how age-related gait adaptation, deterioration of muscular strength and sensory degradation

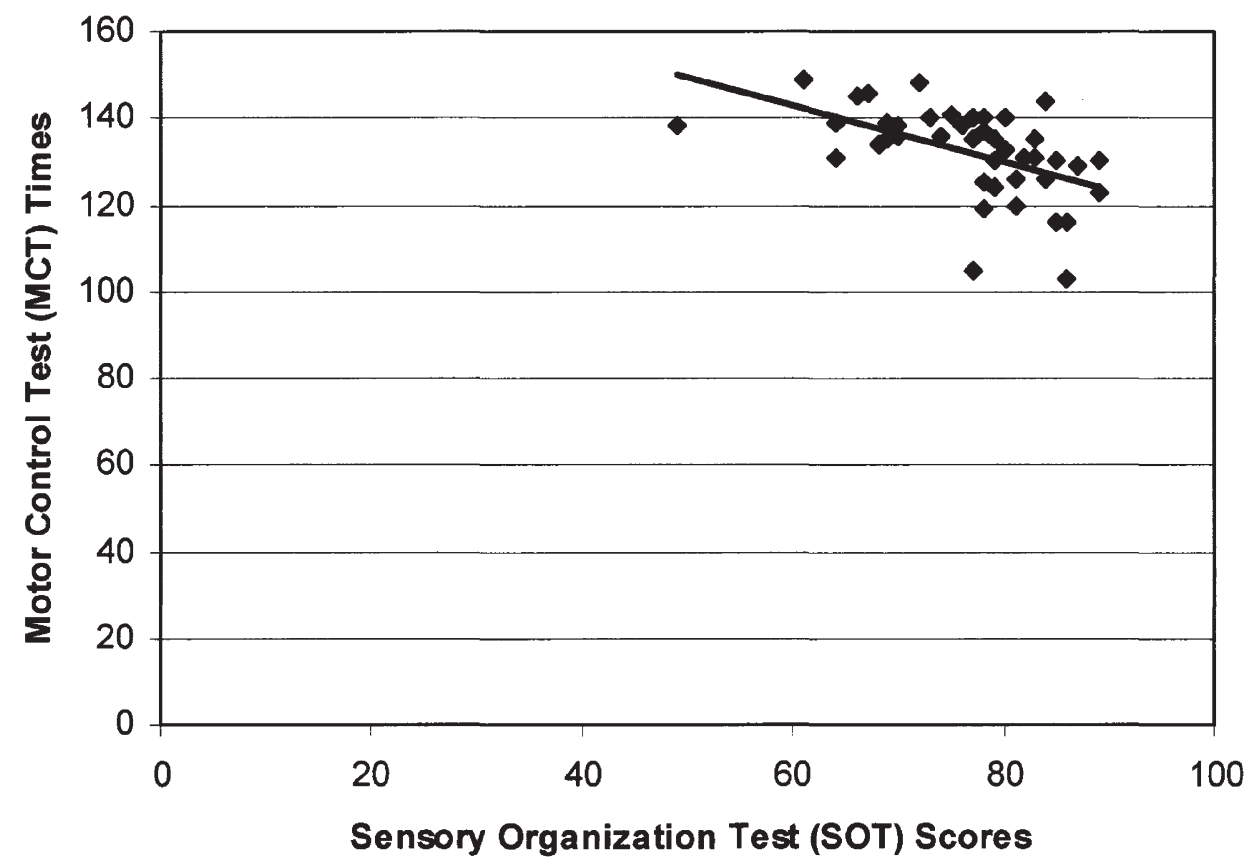

Figure 9. The relationship between SOT scores and MCT times $(r=-.51)$. In general, individuals with higher SOT scores took less time to actively respond to the support surface movements. 


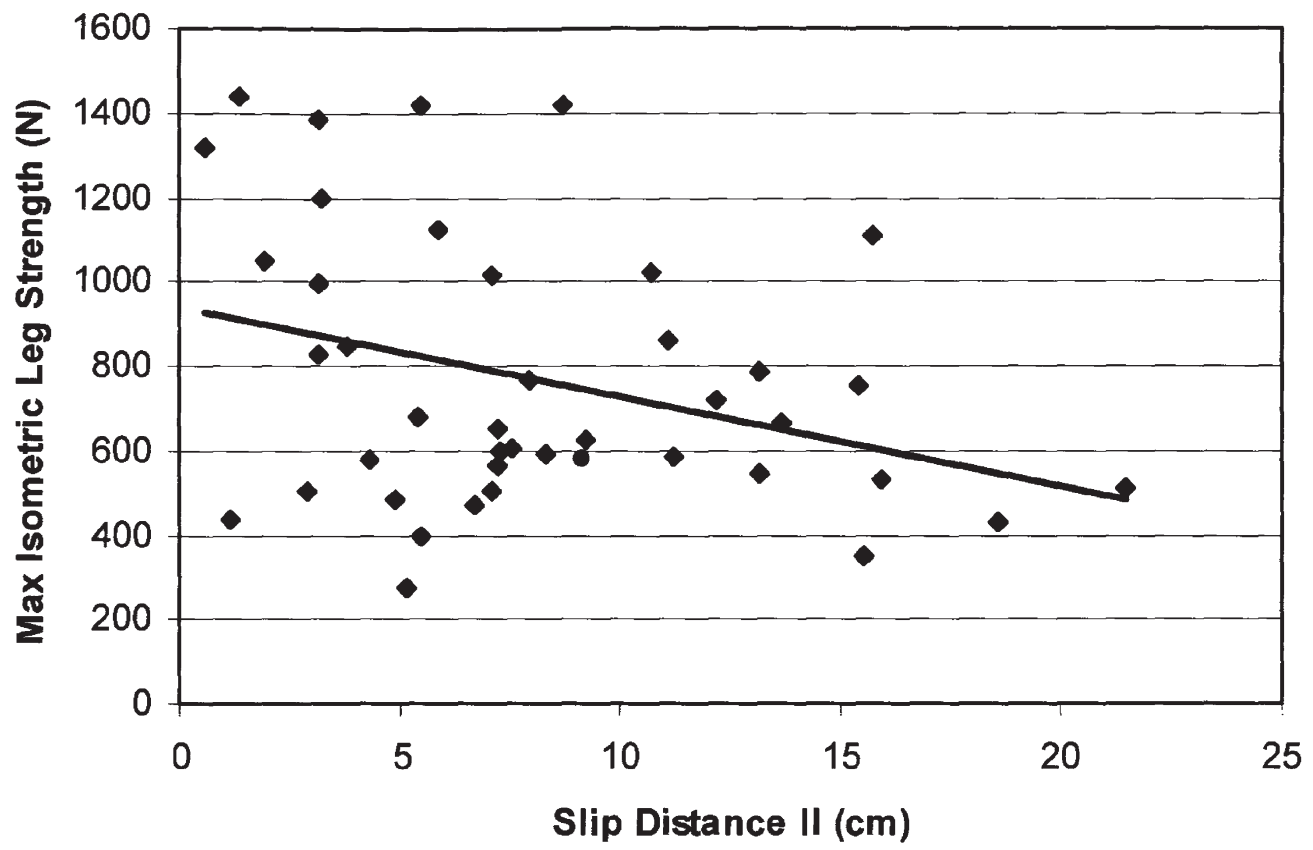

Figure 10. The relationship between maximal isometric leg strength and distance slipped $(r=-0.57)$. In general, individuals with stronger lower extremities slipped less.

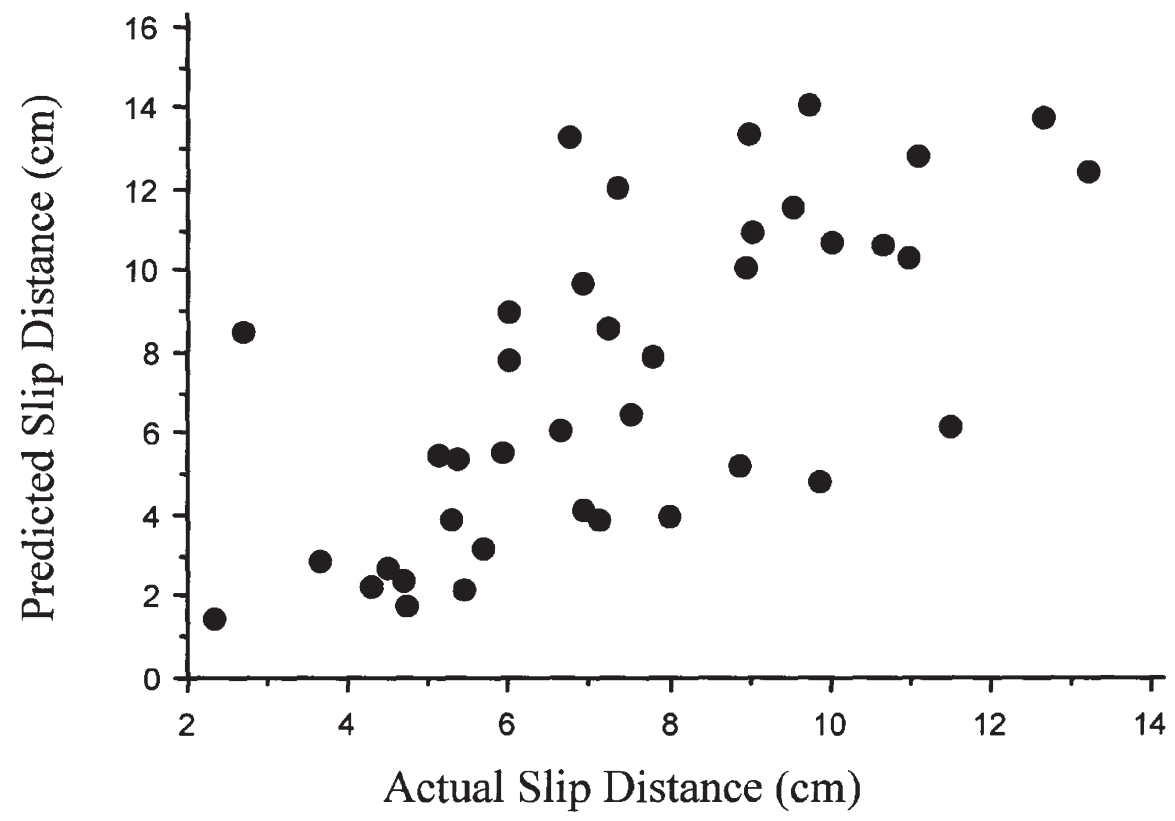

Figure 11. Illustration of actual slip distances and predicted slip distances. The prediction model further suggests that the vision, reaction time, and muscle strength (lower extremity) were important for determining slip distances. 
among older individuals would affect biomechanical parameters of slip and fall accidents under slippery and nonslippery conditions. From the work conducted thus far, we hypothesized that gait adaptations, deterioration of muscular strength, and sensory degradation among older individuals would affect the severity of their slips and falls more than those of their younger counterparts. In particular, it was expected that older adults' gait adaptations would adversely affect the slip initiation process (i.e., would increase the friction demand characteristic at the shoe-floor interface at the time of the heel contact, which would increase the distance slipped initially), leading to more falls. It was also expected that older adults' deterioration of muscular strength and sensory degradation would adversely affect the detection and recovery processes of slip and fall accidents, increasing the speed of slipping and the distance slipped, ultimately leading to more falls.

\section{Slip Initiation Process}

The outcome of a slip-induced fall accident is highly influenced by friction demand characteristics. The works of Perkins and Wilson (1983), Redfern and Andres (1984), and Hanson, Redfern, and Mazumdar (1999) have suggested that the number of slip and fall events will increase as the differences between the friction demand characteristic (i.e., RCOF) and measured dynamic COF increases. Most slips that lead to falls occur when the frictional force opposing the movement of the foot is less than the shear force of the foot immediately after the heel contacts the floor (Perkins, 1978). Furthermore, as indicated by many researchers, initial gait characteristics such as step length, heel contact velocity, and walking velocity may influence the friction demand characteristic because of alterations of the horizontal foot shear force.

In close agreement with previous findings (Mills \& Barrett, 2001; Winter, 1991, pp. 87-94), in this experiment older individuals' step length was significantly shorter and walking velocity (i.e., COM velocity) was significantly slower, as compared with those of their younger counterparts. However, in contrast to previous studies (Lockhart, 1997; Mills \& Barrett, 2001; Winter, 1991), we found no statistically significant differ- ences in heel contact velocity. That no differences were found between young and older adults' heel contact velocity in the present study may be reflective of the selection criterion (which aimed to include only healthy older individuals with no gait abnormalities) or a factor of walking velocity. Regardless of the influencing factors, shorter step length, slower walking velocity, and insignificant differences of heel contact velocity between the young and old groups in this test population suggest that the likelihood of slip initiations is similar across all age groups. This statement is further supported by the finding of no significant differences in initial friction demand characteristics (i.e., RCOF) and initial slip distance (SDI) among the three age groups. Given these results, it seems that older adults in the present study effectively adopted a strategy of stable gait pattern (i.e., shorter step length and slower walking velocity) to reduce the initiation of slipping. Why, then, did older adults in the present study fall more often than their younger counterparts did? The answer may lie hidden in the processes associated with detection of slips and recovery from falls.

\section{Detection and Recovery}

Nashner (1982) suggested that at the time of a potential slip-induced fall, the central nervous system must undertake certain processing stages if a fall is to be avoided or recovered from. First, during the detection of slip perturbation, sensory input must trigger or alert those centers responsible for response selection. This alerting process may be initiated by one or more of the following sensory inputs: proprioception, vision, and vestibular function (Nashner, 1982). Thus any agerelated disruption in the quality of the signal from sensory inputs may increase the likelihood of slip-induced falls because of delayed response selection. Furthermore, after the response selection, muscular strength may play an important role in the recovery process (attenuation of lower extremity motions during slip perturbation) .

In order to investigate the effects of sensory organization on the outcome of slips and falls, we collected equilibrium scores utilizing a computerized dynamic posturography. Similar to previous studies, in our study we found significant equilibrium score differences among the 
three age groups. The results of the Sensory Organization Test (SOT) and associated modalities (somatosensory, vision, and vestibular) indicated that equilibrium scores were lower for older individuals than for their younger counterparts.

In order to provide the relationship between postural control during quiet stance and dynamic slip responses when walking over a slippery floor surface, bivariate correlation analysis between SOT scores and slip distance was performed. The results suggested that individuals with lower SOT scores (sensory degradation) slipped longer. Furthermore, older adults exhibited lower SOT scores along with longer slip distances. Slip behavior utilizing slip distance measures has been investigated by several researchers (Brady, Pavol, Ownings, \& Grabiner, 2000; Perkins, 1978; Strandberg \& Lanshammar, 1981). These investigators found that the severity of a slip (whether the slip resulted in a fall) was dependent on the distance that participants slipped (e.g., any slip distance more than $10 \mathrm{~cm}$ resulted in a fall). This relationship between equilibrium score and slip distance (SDII) suggests that older adults are more likely to fall as a result of a delayed response selection process.

This statement is further supported by the bivariate correlation analysis between the Motor Control Test (MCT) and slip distance (SDII). The relationship between MCT and SDII indicated that individuals with longer motor control times slipped longer, and older adults' motor control time was significantly longer than that of their younger counterparts. Furthermore, the relationships between SOT and MCT suggest that individuals with higher SOT scores took less time to actively respond to the support surface movements.

The effect of the sensory degradation and delayed response selection is further supported by higher adjusted friction utilization (AFU). AFU represents the ability to adjust dynamic frictional requirements during slipping (Gronqvist et al., 2001). The significance of this ratio is that it indicates when the gait compensation for a slip is most likely to occur. On average, the younger individuals' AFU (.074) was adjusted within the dynamic friction requirements (.08). However, on average, the middle-age (AFU .10) and older individuals (AFU .12) could not. Consequently, the result was longer slip distance (SDII) and higher frequency of falls. Thus it seems that sensory degradation among older adults may result in increased frequency of slips and falls because of delayed response selection. In this study, it is important to note that MCT and SOT scores are confounded with age because they were observed as opposed to being manipulated. Additional research that compares younger participants with poor MCT and SOT scores versus older participants with good scores would provide greater insight as to the nature of this effect. As such, although the mechanisms associated with these relationships are implicated, further studies investigating these mechanisms are needed to elucidate this possibility.

Furthermore, muscular strength may have also contributed to older adults' fall frequencies. Do, Breniere, and Brenguier (1982) and Cham and Redfern (2001) suggested that strength generation and the ability to attenuate lower extremity motions are critical in determining whether or not a person can respond appropriately to balance perturbation (i.e., recovery from slips). Evidence in support of this hypothesis comes from a number of investigations indicating an age-related decline in voluntary muscle strength and rate of muscle force production and an increased likelihood of slips and falls. For example, Wolfson et a1. (1985) and Larsson et a1. (1979) reported that ankle and quadriceps muscle strength was significantly lower for those who fall as compared with nonfallers. Additionally, reduced lower extremity strength has been implicated as a factor contributing to nursing home placement (Hubert et al., 1993; Wolfson et al., 1995) and an increased risk of falling (Whipple et al., 1987). In this study, older adults' lower extremities were significantly weaker than those of their younger counterparts (both isometric and isokinetic). A relationship between leg strength and SDII further indicates that individuals with stronger lower extremities slipped less, suggesting that recovery from a slip is associated with lower extremity muscle strength. Further studies investigating the mechanisms associated with muscle force productions and balance recoveries from slip perturbation (i.e., autonomic reflex-like postural responses independent of sensory organizations) are needed to reveal this possibility.

In conclusion, all participants slipped under slippery conditions. However, the older individuals could not control their slips, leading to more falls. Thus, in a given situation, older indi- 
viduals are at a higher risk for fall accidents (i.e., younger individuals can slip longer and faster and not fall). The prediction model further supports the idea that vision, reaction time, and muscle strength (lower extremity) are important for determining slip and fall severity. Inability to control slipping responses may be a result of sensory degradation and muscle weakness. As such, possible intervention strategies (muscle strengthening and balance exercises) can be important for improving dynamic equilibrium for older adults. Furthermore, most of the current research on slips and falls concentrates predominantly on initiation of slips (i.e., RCOF); however, this study indicates that how slips result in a fall is important as well. Therefore, future research should focus not only on the dynamics of slips but also on the dynamics of falls. A principal limitation in the current study may have arisen from the situation of inadvertency. Unexpected slips and falls were introduced utilizing the methods described. However, as in all laboratory experiments, a tendency to anticipate "complete unexpectedness" will be limited by equipment and laboratory settings. In order to avoid such anticipation, we had participants walk at a natural cadence for approximately $15 \mathrm{~min}$ prior to introducing the slippery surface. A comparison of the gait parameters (e.g., step length, heel contact velocity, and walking velocity) between the nonslippery and slippery floor surfaces suggest, although speculatively, that the participants' walking characteristics were consistent throughout the experiment. Previous studies investigating gait pattern modification suggested that when participants knew they were walking onto a slippery floor surface, they tended to shorten their step length and reduce walking velocity (Ekkubus \& Killey, 1973; Lockhart, 1997). The lack of significant differences in step length, heel contact velocity, and walking velocity between the slippery and nonslippery floor surfaces suggests that our participants were unaware of the floor surface change and thus did not alter their gait characteristics when stepping onto the slippery floor surface.

Furthermore, the model of slips and falls in this study does not include the information-processing capabilities of the individuals. As such, our results may be confounded by an individual's ability to process critical information in a timely manner. Future studies should link a hu- man information-processing paradigm and biomechanics of reactive recovery during slip perturbation to refine the model of slips and falls.

\section{Acknowledgments}

This research was supported by the National Institutes of Health (National Institute for Occupational Safety and Health) Grant R03/Small Grant 1-R03-0803917-01. The paper's contents are solely the responsibility of the authors and do not necessarily represent the official views of the National Institutes of Health.

\section{References}

Agnew, J., \& Suruda, A. J. (1993). Age and fatal work-related falls. Human Factors, 35,731-736.

American Geriatrics Society, British Geriatrics Society, \& American Academy of Orthopaedic Surgeons Panel on Falls Prevention. (2001). Guideline for the prevention of falls in older persons. Journal of the American Geriatrics Society, 49, 664-672.

Astrand, P. 0., \& Rodahl, K. (1986), Textbook of work physiology. New York: McGraw-Hill.

Bard c., Fleury M., Teasdale N., Paillard J., \& Nougier, V. (1995). Contribution of proprioception for calibrating and updating the motor space. Canadian Journal of Physiology and Pharmacology, 73, 246-254.

Black, F. O. (2001). Clinical status of computerized dynamic posturography in neurotology. Current Opinion in Otolarynogology - Head and Neck Surgery, 9, 314-318.

Bonder, B. R., \& Wagner, M. B. (1994). Functional performance in older adults. Philadelphia: F. A. Davis.

Brady, R. A., Pavol, M. J., Owings, T. M., \& Grabiner, M. D. (2000). Foot displacement but not velocity predicts the outcome of a slip induced in young subjects while walking. Journal of Biomechanics, 33, 803-808.

Brocklehurst, J. C., Robertson, D., \& James-Groom, P. (1982). Clinical correlates of sway in old age - Sensory modalities. Age and Ageing, 11, 1-10.

Campbell, A. J., Reinken, J., Allan, B. c., \& Martinez, G. S. (1981). Falls in old age: A study of frequency and related factors. Age and Ageing, 10, 264-270.

Chaffin, D. B., \& Andersson, G. B. J. (1991). Occupational biomechanics. New York: Wiley.

Chaffin, D. B., Herrin, G. D., \& Keyserling, W M. (1978). Preemployment strength testing, Journal of Occupational Medicine, 20, 403--408.

Chaffin, D. B., Woldstad, J. c., \& Trujillo, A. (1992). Floor/shoe slip resistance measurement. American Industrial Hygiene Association Journal, 53, 283-289.

Cham, R., \& Redfern, M. S. (2001), Lower extremity corrective reactions to slip events. Journal of Biomechanics, 34, 1439-1445.

Cohen, H., Heaton, L. G., Congdon, S. L., \& Jenkins, H. A. (1996). Changes in sensory organization test scores with age. Age and Ageing, 25, 39--44.

Cohn, T. E., \& Lasley, D. J. (1985). Visual depth illusion and falls in the elderly. Clinics in Geriatric Medicine, 1, 601-610. Cooper, J. M., \& Glassow, R. B. (1963). Kinesiology. New York: 
Mosby.

Courtney, T. K., Sorock, G. S., Manning, D. P., Collins, J. W, \& Holbein-Jenny, M. A. (2001). Occupational slip, trip, and fall-related injuries - Can the contribution of slipperiness be isolated. Ergonomics, 44, 1118-1137.

Do, M, C, Breniere, Y., \& Brenguier, P, (1982) A biomechanical study of balance recovery during the fall forward, Journal of Biomechanics, 15, 933-939,

Donald, L P., \& Bulpitt, C J. (1999). The prognosis of falls in elderly people living at home. Age and Ageing, 28, 121-125.

Ekkubus. C F., \& Killey. W. (1973). Validity of 0.5 static coefficient of friction (James Machine) as a measure of safe walkway surfaces. Soap/Cosmetics/Chemical Specialties, 49(2),40-45

El-Kashlan, (n.i.), Hussam. K., Shaepard, N. T., Asher, A. M .. Smith-Wheelock, M., \& Telian, S. A. (1998). Evaluation of clinical measures of equilibrium. Laryngoscope, 108, 311-319.

Englander E, Hodson, T. J., \& Terregrossa, R. A. (1996), Economic dimensions of slip and fall injuries. Journal of Forensic Science, 41,733-746.

Ford-Smith, C., Wyman, J., Elswick. R. K., \& Fernandez, T. (1995). Test-retest reliability of the sensory organization test in noninstitutionalized older adults. Archives of Physical Medicine and Rehabilitation, 76, 77-81.

Ghez. C., \& Sainburg, R. L. (1995). Proprioceptive control of interjoint coordination. Canadian Journal of Physiology and Pharmacology, 73, 273-284.

Gillis, B., Gilroy, K., Lawley, H., Mott, L., \& Wall, J. C. (1986). Slow walking speeds in healthy young and elderly females. Physiotherapy Canada, 38, 350-352.

Goldman, R. (1986). Decline in organ function with aging. In I. Rossman (Ed.), Clinical geriatrics (pp. 23-59). Philadelphia: Lippincott.

Gronqvist, R., Abeysekera. J., Gard, G., Hsiang, S. M., Leamon, T. B., Newman, D. J., et al. (2001). Human-centered approaches in slipperiness measurement. Ergonomics, 44, 1167-1199.

Hanson, J. P., Redfern, M. S., \& Mazumdar, M. (1999). Predicting slips and falls considering required and available friction, Ergonomics, 42, 1619-1633.

Houmard, J. A., Weidner, M. L., Gavigan, K. E., Tyndall. G. L., Hickey, M. S., \& Alshami, A (1998). Fiber type and citrate synthase activity in the human gastrocnemius and vastus lateralis with aging. Journal of Applied Physiology, 85, 1337-1341.

Hubert, H. B., Bloch, D. A, \& Fries, J. E (1993). Risk factors for physical disability in an aging cohort: The NHANES I epidemiologic follow-up study. Journal of Rheumatology, 20, 480-488.

Imms, E J., \& Edholm, O. G. (1979). The assessment of gait and mobility in the elderly. Age and Ageing, 8, 261-267.

Inglis. J. T., Shupert, C. L., Hlavacka, E. \& Horak, E B. (1995). Effect of galvanic vestibular stimulation on human postural responses during support surface translations. Journal of Neurophysiology, 73, 896--901.

Isaacs, B. (1985). Clinical and laboratory studies of falls in old people. Clinics in Geriatric Medicine, 1, 513-524.

Johnsson, L. G., \& Hawkins, J. E., Jr. (1972). Sensory and neural degeneration with aging, as seen in microdissections of the inner ear. Annals of Otology, Rhinology and Laryngology, 81, 179-193.

Judge. J. 0., Lindsey, c., Underwood, M., \& Winsemius, D. (1993). Balance improvements in older women: Effects of exercise training. Physical Therapy, 73, 254-265.
Keshner, E. A., Allum, J. H. J., \& Pfaltz, C. R. (1987), Postural activation and adaptation in the sway stabilizing responses of normals and patients with bilateral deficit. Experimental Brain Research, 69, 77-92.

Kornzweig, A L. (1977). Visual loss in the elderly. Hospital Practice, 12,51-59.

Kristinsdottir, K. E., Jarnlo. G.-B .. \& Magnusson, M. (2000). Asymmetric vestibular function in the elderly might be a significant contributor to hip fractures. Scandinavian Journal of Rehabilitation Medicine, 32, 56--60.

Lacour, M., Vidal, P. P.. \& Xerri, C. (1983). Dynamic characteristics of vestibular and visual control of rapid postural adjustments. In J. Desmedt (Ed.), Motor control mechanisms in health and disease (n.p.). New York: Raven Press.

Larsson, L. (1982). Aging in mammalian skeletal muscle. In J. A Mortimer, P. J. Pirazzolo, \& G. J. Meletta (Eds.). The aging motor system (n.p.). New York: Praeger.

Larsson, L.. Grimby, G., \& Karlsson, J. (1979). Muscle strength and speed of movement in relation to age and muscle morphology. Journal of Applied Physiology, 46, 451-456.

Lexell, J. (1995). Human aging, muscle mass, and fiber type composition. Journal of Gerontology, Series A, 50A (Suppl.), 11-16.

Lockhart, T. E. (1997). The ability of elderly people to traverse slippery walking surfaces. In Proceedings of the Human Factors and Ergonomics Society 41st Annual Meeting (125-129). Santa Monica, CA: Human Factors and Ergonomics Society.

Lockhart, T. E., Woldstad, J. c., \& Smith, J. L. (2002). Assessment of slip severity among different age groups: Metrology of pedestrian locomotion and slip resistance. ASTM STP, 1424, $17-32$.

Lockhart, T. E., Woldstad, J. C., \& Smith, J. L. (2003). Effects of age-related gait changes on biomechanics of slips and falls. Ergonomics, 46, 1136-1160.

Lord. S. R., Clark, R. D., \& Webster I. W. (1991). Visual acuity and contrast to sensitivity in relation to falls in an elderly population. Age and Ageing, 20, 175-181.

Mackinnon, C. D., \& Winter, D. A. (1993). Control of whole body balance in the frontal plane during human walking. Journal of Biomechanics, 26,633-644.

Maki, B. E., Holliday, P. J .. \& Topper, A. L (1994). A prospective study of postural balance and risk of falling in an ambulatory and independent elderly population. Journal of Gerontology, 104,480-492.

Melvill, J. G., \& Watt, D. G. D. (1971a). Muscular control of landing from unexpected falls in man. Journal of Physiology (London), 219,729-737.

Melvill, J. G., \& Watt, D. G. D. (1971b). Observations on the control of stepping and hopping movements in man. Journal of Physiology (London), 219, 709-727.

Mills, P., \& Barrett, R. (2001). Swing phase mechanics of healthy young and elderly men. Human Movement Science, 20, 427-446.

Murphy, S. L. (2000). Deaths: Final data for 1998 (National Vital Statistics Reports, Vol. 48, No. 11). Hyattsville, MD: National Center for Health Statistics.

Murray, M. P., Kory, R. c., \& Clarkson, B. H. (1969). Walking patterns in healthy old men. Journal of Gerontology, 24, 169-178.

Nashner, L. M. (1982). Analysis of movement control in man using the movable platform. In J. Desmedt (Ed.), Motor control mechanisms in health and disease (n.p.). New York: Raven Press.

Nashner, L. M., Black, F. O., \& Wall, C. (1982). Adaptation to altered support and visual conditions during stance: Patient 
with vestibular deficits. Journal of Neuroscience, 5, 117-124. National Safety Council. (2002). Accidents facts. Itasca, IL: Author.

Nevitt, M. C., Cummings, S. R., Kidd, S., \& Black, D. (1989). Risk factors for recurrent nonsyncopal falls: A prospective study. Journal of the American Medical Association, 261, 2663-2668.

Norton, R., Campbell, J., Lee-Joe, T., Robinson, E., \& Butler, M. (1997). Circumstances of falls resulting in hip fractures among older people. Journal of the American Geriatrics Society, 45, 1108-1112.

Overstall, P. w., Exton-Smith, AN., Imms, E J., \& Johnson, A L. (1977). Falls in the elderly related to postural imbalance. British Medical Journal, 1, 261-264.

Perkins, P. J. (1978). Measurement of slip between the shoe and ground during walking. ASTM STP, 649, 71-87.

Perkins, P. J., \& Wilson, M. P. (1983). Slip resistance testing of shoes - New developments. Ergonomics, 26, 73-82.

Petersen, H., Magnusson, M., Fransson, P.-A., \& Johansson, R. (1994). Vestibular disturbances at frequencies above $1 \mathrm{~Hz}$ affect human postural control. Acta Oto-Laryngologica (Stockholm), 114, 225-230.

Rabbitt, P., \& Rogers, M. (1965). Age and choice between responses in a self-paced repetitive task. Ergonomics, 8, 435-444.

Redfern, M. S., \& Andres, R. O. (1984). The analysis of dynamic pushing and pulling: Required coefficients of friction. In Proceedings of the 1984 International Conference on Occupational Ergonomics, Ontario (pp. 569-571). Mississauga, Canada: Human Factors Association of Canada.

Redfern, M. S., \& DiPasquale, J. D. (1997). Biomechanics of descending ramps. Gait and Posture, 6, 119-125.

Rice, C. L.. \& Cunningham, D. A (2001). Aging of the neuromuscular system: Influences of gender and physical activity. In R. J. Shephard (Ed.), Gender, physical activity, and aging (pp. 212-250). Boca Raton, FL: CRC Press.

Rosenhall, U., \& Rubin, W. (1975). Degenerative changes in the human vestibular sensory epithelia. Acta Oto-Laryngologica (Stockholm), 79, 67-80.

Rubenstein, L. Z., Robbins, A. S., Schulman, B. L., Rosado. J., Osterweil, D. \& Josephson, K. R. (1988). Falls and instability in the elderly. Journal of the American Geriatrics Society. 36. 266-278.

Ruckenstein. M. J .. \& Shepard. N. T. (2000). Balance function testing: A rational approach. Otolaryngologic Clinics of North America, 33, 507-518.

Sainburg. R. L.. Ghilardi. M. F.. Poizner. H .. \& Ghez. C. (1995). The control of limb dynamics in normal subjects and patients without proprioception. Journal of Neurophysiology, 73, 820-835.

Sheldon, J. H. (1963). The effect of age on the control of sway. Gerontologia Clinica, 5, 129-138.

Skinner. H. B .. Barrack. R. L.. \& Cook. S. D. (1984). Age-related decline in proprioception. Clinical Orthopaedics, 184. 208-211.

Stelmach. G. E .. \& Worringham. C. J. (1985). Sensimotor deficits related to postural stability: Implications for falling in the elderly. Clinics in Geriatric Medicine, 1,679-694.

Stephen. R.. John. A.. Philippa. w.. \& Kaarin. J. (1994). Physiological factors associated with falls in older communitydwelling women. Journal of the American Geriatrics Society, 42, 1110-1117.

Strandberg. L., \& Lanshammar. H. (1981). The dynamics of slipping accidents. Journal of Occupational Accidents. 3, 153-162.
Thelen, D. G .. Schultz. A. B .. Alexander. N. B .. \& AshtonMiller. J. A. (1996). Effects of age on rapid ankle torque development. Journal of Gerontology: Medical Sciences, 51A. M226-M232.

Tinetti. M. E. (2003). Clinical practice: Preventing falls in elderly persons. New England Journal of Medicine, 348, 42-49.

Tinetti. M. E .. Liu. W. L.. \& Claus. E. (1993). Predictors and prognosis of inability to get up after falls among elderly persons. Journal of the American Medical Association, 269, 65-70.

Tinetti. M. E . \& Speechley, M. (1989). Prevention of falls among the elderly. Medical Intelligence. 320, 1055-1059.

Tinetti. M. E .. Speechley. M . \& Ginter. S. F. (1988). Risk factors for falls among elderly persons living in the community. New England Journal of Medicine. 319, 1701-1707.

Whipple. R. H .. Wolfson, L. I.. \& Amerman, P. M. (1987). The relationship of knee and ankle weakness to falls in nursing home residents: An isokinetic study. Journal of the American Geriatrics Society, 35, 13-20.

Winter. D. A. (1990). Biomechanics and motor control of human movement (2nd ed.). New York: Wiley.

Winter. D. A. (1991). The biomechanics and motor control of human gait: Normal, elderly and pathological (2nd ed.). Waterloo. Canada: University of Waterloo Press.

Winter. D. A .. Patla. A. E .. Frank. J. S., \& Walt. S. E. (1990). Biomechanical walking pattern changes in the fit and healthy elderly. Physical Therapy, 70, 340-347.

Wolfson L.. Judge, J., Whipple, R., \& King, M. (1995). Strength is a major factor in balance. gait, and the occurrence of falls. Journal of Gerontology, 50A, 64-67.

Wolfson, L., Whipple, R., Amerman, P., Kaplan. J., \& Kleinberg, A. (1985). Gait and balance in the elderly. Clinics in Geriatric Medicine, 1, 649-659.

Woolacott, M. H. (1986). Aging and postural control: Changes in sensory organization and muscular coordination. International Journal of Aging and Human Development, 23,97-101.

Woolacott, M. H., Shumway-Cook. A.. \& Nashner. L. (1982). Postural reflexes and aging. In J. A. Mortiner, F. J. Pirozzolo, \& G. J. Maletta (Eds.). The aging motor system (n.p.). New York: Praeger.

Thurmon E. Lockhart is an assistant professor of industrial and systems engineering and the director of the Locomotion Research Laboratory at Virginia Polytechnic Institute and State University, Blacksburg, Virginia. He received his Ph.D. in industrial engineering at Texas Tech University in 2000.

James L. Smith is a professor of industrial engineering at Texas Tech University, Lubbock, Texas. He received his Ph.D. in industrial engineering at the University of Auburn in 1980.

Jeffrey C. Woldstad is an associate professor of industrial and manufacturing engineering at Oregon State University, Corvallis, Oregon. He received his Ph.D. in industrial engineering at the University of Michigan in 1989.

Submitted May 19, 2003; accepted April 3, 2005. 